\title{
Flexible Hybrid Electrodes for Continuous Measurement of the Local Temperature in Long-Term Wounds
}

\author{
Ana María Rodes-Carbonell ${ }^{1, *}$, Juan Torregrosa-Valls ${ }^{2}\left(\mathbb{D}\right.$, Antonio Guill Ibáñez ${ }^{3}$, Alvaro Tormos Ferrando ${ }^{3}$, \\ María Aránzazu Juan Blanco ${ }^{2}$ and Antonio Cebrián Ferriols ${ }^{3}$ (D) \\ 1 Instituto Tecnológico del Textil (AITEX), 03801 Alcoy, Spain \\ 2 Faculty of Medicine and Health Sciencies, Universidad Católica de Valencia San Vicente Martir, \\ 46001 Valencia, Spain; juan.torregrosa@ucv.es (J.T.-V.); ma.juan@ucv.es (M.A.J.B.) \\ 3 Electronic Engineering Department, Universitat Politècnica de València, 46022 Valencia, Spain; \\ aguill@eln.upv.es (A.G.I.); atormos@eln.upv.es (A.T.F.); acebrian@eln.upv.es (A.C.F.) \\ * Correspondence: arodes@aitex.es
}

check for

updates

Citation: Rodes-Carbonell, A.M.; Torregrosa-Valls, J.; Guill Ibáñez, A.; Tormos Ferrando, A.; Juan Blanco,

M.A.; Ferriols, A.C. Flexible Hybrid Electrodes for Continuous Measurement of the Local Temperature in Long-Term Wounds. Sensors 2021, 21, 2741. https:// doi.org/10.3390/s21082741

Academic Editor: Marco Di Rienzo

Received: 22 March 2021

Accepted: 9 April 2021

Published: 13 April 2021

Publisher's Note: MDPI stays neutral with regard to jurisdictional claims in published maps and institutional affiliations.

Copyright: (c) 2021 by the authors. Licensee MDPI, Basel, Switzerland. This article is an open access article distributed under the terms and conditions of the Creative Commons Attribution (CC BY) license (https:// creativecommons.org/licenses/by/ $4.0 /)$.

\begin{abstract}
Long-term wounds need a continuous assessment of different biophysical parameters for their treatment, and there is a lack of affordable biocompatible devices capable of obtaining that uninterrupted flow of data. A portable prototype that allows caregivers to know the local temperature behavior of a long-term wound over time and compare it with different reference zones has been developed. Alternative flexible substrates, screen-printing techniques, polymeric inks, and an embedded system have been tested to achieve potential indicators of the status and evolution of chronic wounds. The final system is formed by temperature sensors attached to a flexible and stretchable medical-grade substrate, where silver conductive tracks have been printed as interconnections with the data-acquisition unit. In addition, a specific datalogger has been developed for this system. The whole set will enable health personnel to acquire the temperature of the wound and its surroundings in order to make decisions regarding the state and evolution of the wound.
\end{abstract}

Keywords: lower extremity wound; wound temperature; infection; inflammation; wound continuous monitoring; screen printing; printed sensors; flexible hybrid electronics

\section{Introduction}

Long-term wounds represent one of the most important causes of morbidity and mortality for patients with chronic diseases such as diabetes or venous insufficiency. Likewise, those caused by physical factors like pressure, friction, or shearing are characteristic of bedridden patients [1]. Currently, these injuries are a challenge for professionals who apply advanced wound care, and represent a high cost to both human and economic resources [2].

Long-term wound healing requires cellular activities that need an optimal specific environment to take place in the right form and time. Wound healing strongly depends on different biophysical parameters such as temperature or $\mathrm{pH}$. The proper evolution of these parameters enables the transition through the different healing phases (hemostasis, inflammation, proliferation, and remodeling/epithelialization), thereby promoting local homeostasis. On the other hand, their alteration may result in a delay of the wound healing [3], or even in an infection by indigenous or external microorganisms. The management, treatment, and monitoring of these wounds is mainly based on clinical expertise and qualitative methods with a high subjectivity level. The evolution of these biophysical parameters is not estimated quantitatively. This is because the measuring devices only allow sporadic quantification, as they require complex calibrations with a high cost. Additionally, these measurements may be biased by a difficult anatomical morphology, the environment where they are performed, the technique, and the dimensions of the probes used.

There is currently great interest in measuring these wound characteristics, since they involve potential indicators and predictors of the evolution healing [4]. The wound 
anatomy needs to be locally delineated. Each anatomical region will have a meaning in the subsequent interpretation of the results obtained from the measurement of the characteristics of the wound. Wounds International divides the wound into two anatomical regions of great interest: the wound bed and the periwound skin. The wound bed is the region where there is a solution of continuity and where the tissues below the epidermis are exposed, be they subcutaneous tissue, fasciae, muscles, tendons, or bone. According to Dowsett and Hallern, the perilesional skin is considered as the distance between the wound edge and the 4 centimeters of skin that surrounds the wound-bed perimeter. This region faces a series of challenges during the wound-care process due to its influence on the healing prognosis, and therefore acquires great relevance in the objective assessment of the wound. Continuous assessment of the zone around the wound through indicators can help to make objective the abstract phenomenon of healing. Quantifying the state of the wound bed, its edge, and the state of the perilesional skin will allow caregivers to dynamically assist treatment plans and to compare results, reducing the healing time. The determination of these results is the key to the research in healthcare. All the changes achieved in those indicators can be considered the results from the interventions over the wounds.

New organic substrates such as polyurethane (PU), polydimethylsiloxane (PDMS), polyethylene terephthalate (PET), indium and tin oxide (ITO), or polyaniline (PANi) allow circuit printing using techniques such as screen printing. This enables the development of continuous wound sensing and monitoring systems that require certain characteristics. A series of conductive tracks based on high-conductivity electronic inks are printed on these substrates by screen printing. These tracks serve as an interface between the sensor and the acquisition system. Following the same manufacturing technique, Milne in 2014 [5] and Rahimi in 2015 [6] proposed a $\mathrm{pH}$ measurement system printed on an ion-selective membrane, using a reference electrode composed of $\mathrm{Ag} / \mathrm{AgCl}$ printed in the same way. Later, they developed a humidity sensor based on the same system of polymeric silver inks on PU [7]. This manufacturing technique used by the previous authors was characterized by Suikkola in 2016 [8]. On the other hand, authors such as Matzeu and Salvo [9,10] developed sensory-resistive sensors for continuous temperature measurement using materials such as polyimide (Kapton) and integrated graphene nanotubes. All these sensors met the requirements for reliability and flexibility, although their reuse and biocompatibility are not entirely known due to the use of components not tested in humans.

Although these technologies have points of similarity, the choice of different textiles and films provide differentiating characteristics between them. Flexible substrates like PU and PDMS can be reusable and sterilizable, as they are not associated with singleuse wound dressings. They have elasticity and are adaptable to the body morphology. Furthermore, their biocompatibility has been demonstrated [11,12].

Among the measurable parameters that can be highlighted are $\mathrm{pH}$ and temperature, which Kassanos achieved to measure using electrochemical deposition [13,14]. There also are more complex ones, such as transepidermal water loss (TEWL). Of these, temperature is a simple parameter to interpret that can provide interesting information regarding the state of chronic wounds (CWs). The temperature in the wound bed should be between 31 and $35^{\circ} \mathrm{C}$, while in the perilesional skin it should be between 31 and $34^{\circ} \mathrm{C}$ [15]. Temperatures around $33^{\circ} \mathrm{C}$ are necessary for optimal cellular processes [16].

Armstrong et al. suggested that changes in the temperature gradients in different locations of the wound, compared to reference areas, are indicators of the presence of inflammation, infection and, in the absence of these, the evolution toward healing [3]. Feirheller et al. reported a connection between the increase in perilesional skin temperature regarding the bed temperature, and the presence of infection. They recommended the inclusion of the measurement of these gradients in the routine assessment of CWs [17].

Mufti [18] compared the most popular techniques, such as thermography and infrared thermometry, with four-point measurement protocols. Despite being reliable, both techniques only allowed discontinuous measurements and were influenced by the environment. In contrast, although contact thermometry is less used, it lacks some of the main limita- 
tions presented and allows continuous measurements of this parameter with an adequate system $[19,20]$. Objectification of the wound's assessment becomes necessary to guide the treatments. Long-term wounds are a silent epidemic with a high social, professional, and economic burden, so techniques and devices are sought to reduce costs, shorten healing time, and improve the patient's quality of life.

The ease of access and cost of manufacturing techniques mentioned above allow the manufacturing of devices able to assist in monitoring and control the status of this type of wound. The purpose of this research is to develop a continuous measurement system for temperature differentials. It will be based on flexible and elastic medical grade PU substrates that are able to adapt to the morphology of the wound. It will be marked by high autonomy, as well as low impact on the body and on the patient's mobility. With it, it will be possible to detect critical changes related to inflammation and infection that aggravate and prolong a wound.

\section{Materials and Methods}

\subsection{Sensor Design}

A prototype has been developed to be used in chronic wounds in order to gather longitudinal information about the temperature evolution. The system allows caregivers to know the behavior of the local temperature of the wound over time and to compare it with different reference areas (proximal and perilesional).

The prototype consists of two main blocks, a temperature multisensor and an electronic system for measuring, storing, and managing data. The main features of each block are detailed in Table 1.

Table 1. Characteristics of the prototype.

\begin{tabular}{ll}
\hline General & $\checkmark$ Lightweight, small dimensions, with the ability to store information for later analysis \\
& $\checkmark$ Temperature sensor isolated by biocompatible systems allowing contact with healthy skin and the wound itself \\
& $\checkmark$ Minimal impact on the cellular processes of the skin \\
& $\checkmark$ Adaptable to the anatomical morphology of the wound \\
& $\checkmark$ Reusable by sterilization \\
& $\checkmark$ Biocompatible materials to minimize the risk of allergic reactions and rejections \\
& $\checkmark$ Simple connectivity to the acquisition system \\
& $\checkmark$ Durability when it is in contact with the wound \\
& $\checkmark$ Small dimensions \\
& $\checkmark$ Lightweight \\
& $\checkmark$ Large data storage capacity \\
Electronic Block & $\checkmark$ Low energy consumption \\
& $\checkmark$ Data upload to PC via USB \\
& $\checkmark$ Simple software interface \\
& $\checkmark$ Real-time measurements \\
\hline
\end{tabular}

The multisensor block comprises the sensors that will facilitate, in contact with the wound and the reference areas, the acquisition of the temperatures of interest.

The electronic system is responsible for the quantification, storage, and management of the information gathered. It will be made up of a microprocessor for the acquisition of the signal generated by the sensors, a recording unit, and the necessary components for data transmission.

\subsection{Multisensors}

Figure 1 shows the sensor system, and the multisensor block is detailed. This part is composed of a biocompatible flexible substrate on which conductive tracks are screenprinted using high-conductivity inks, thus connecting the temperature sensors with the connectors of the electronic system. There are four sensor elements for measuring the 
temperature of the wound $(\mathrm{Tu})$, the periwound zone $(\mathrm{Tp})$, the healthy skin as reference (Tr), and the environmental (Ta). The sensors are PDMS-coated to avoid direct contact of the sensor with the injury or the skin. The rest of the substrate is also protected with a second layer of heat-sealed PU film, thus avoiding direct contact with the conductive inks. The substrates and the silver conductive inks are flexible and stretchable, so they can be adapted to any shape and length.

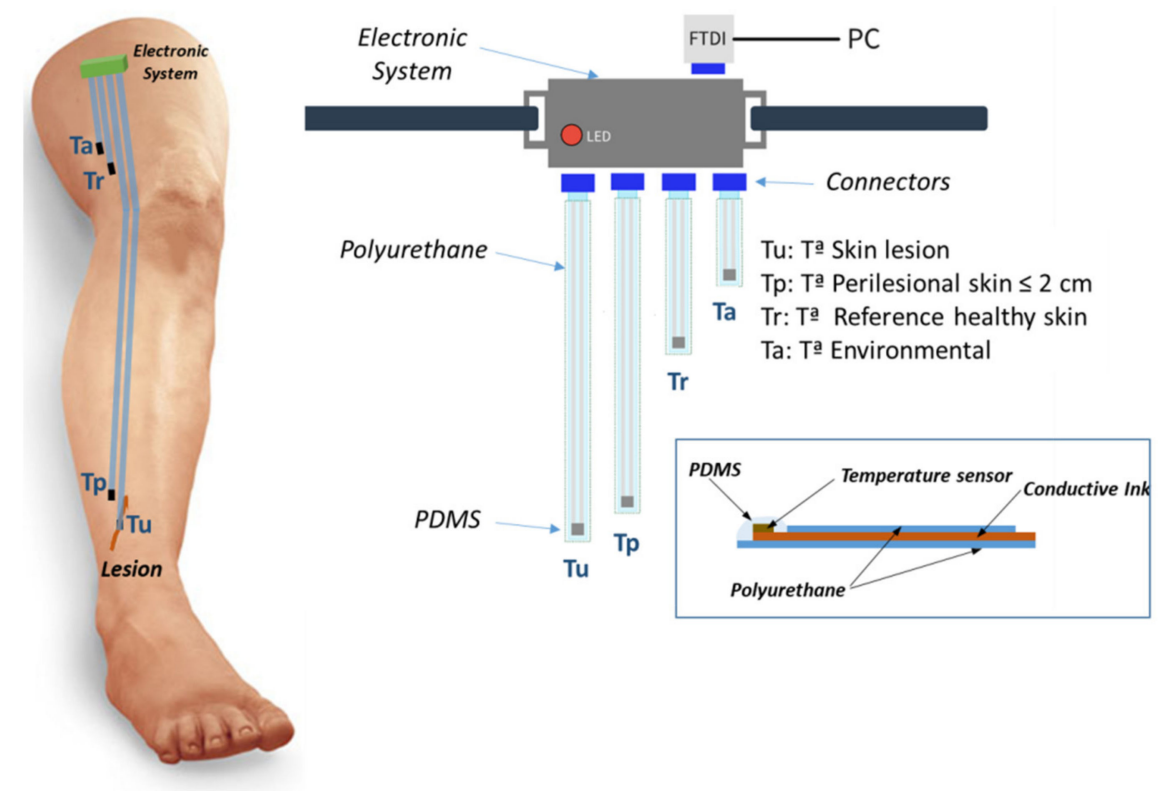

Figure 1. Sensor system configuration: the electronic measurement, data storage, and transmission system are attached to the leg by means of an extensible tape. The different temperature sensors placed in the areas detailed in the figure are connected to this system. The entire sensor system is covered with a compression bandage (not shown in the figure).

For the sensor-element selection, several requirements have been considered, which are detailed in Table 2.

Table 2. Temperature sensor requirements.

\begin{tabular}{cc}
\hline Parameters & Specifications \\
\hline Temperature resolution & $0.1^{\circ} \mathrm{C}$ \\
Support & Flexible and able to be adapted to the contour of the limb and the injury \\
Size & $10 \mathrm{~mm}^{2}$ maximum \\
Encapsulation & Surface-mount technology (SMT) \\
In contact with the wound bed \\
Control sensor location \\
Environmental sensor location \\
Power \\
Material & $\begin{array}{c}\text { In contact with healthy/perilesional skin } \\
\text { In the bandage, without skin contact }\end{array}$ \\
Low energy \\
Biocompatible
\end{tabular}

The commercial sensor model used is the NTCS0805E3104SMT from Vishay (Malvern, PA, USA). It is a negative temperature coefficient (NTC) thermistor, the main characteristics of which are shown in Table 3. The sensor encapsulation has a surface of $2.5 \mathrm{~mm}^{2}$ and a low enough profile to avoid discomfort or injuries caused by pressure on the wound. 
Table 3. Characteristics of the NTCS0805E3104SMT sensor.

\begin{tabular}{cc}
\hline Parameter & Value \\
\hline Resistance value at $25{ }^{\circ} \mathrm{C}(\Omega)$ & $100 \mathrm{k}$ \\
Tolerance on R25-value $(\%)$ & 1 \\
B25/85-value $(\mathrm{K})$ & 3590 \\
Tolerance on B25/85-value $(\%)$ & \pm 1 \\
Maximum power dissipation $(\mathrm{mW})$ & 210 \\
Response time $(63.2 \%) 25^{\circ} \mathrm{C}$ to $85^{\circ} \mathrm{C}$ still air $(\mathrm{s})$ & 10 \\
Dissipation factor $\delta$ in still air $(\mathrm{mW} / \mathrm{K})$ & 3.5 \\
Operating temperature range $\left({ }^{\circ} \mathrm{C}\right)$ & -40 to +125 \\
Weight $(\mathrm{mg})$ & 8 \\
Dimensions $\mathrm{L} \times \mathrm{W} \times \mathrm{T}(\mathrm{mm})$ & $2.0 \times 1.25 \times 0.8$ \\
\hline
\end{tabular}

With these premises, the dimensions of the multisensor element are shown in Figure 2. The total length is $47 \mathrm{~cm}$, determined by the length of the injury temperature sensor (Tu). The periwound sensor (Tp) measures $45 \mathrm{~cm}$, the reference sensor (Tr) measures $31 \mathrm{~cm}$, and the environmental temperature sensor $(\mathrm{Ta})$ is $26 \mathrm{~cm}$ long. A unique eight-pin connector has been chosen to facilitate connection to the electronics. The end of the substrate has the required dimensions for the correct positioning of the connector (track size of $1.5 \mathrm{~mm}$ and $1 \mathrm{~mm}$ of pitch). The length of the connecting tracks is $30 \mathrm{~mm}$. At each end where the sensors are located, a soldering zone has been designed for the NTC with an 0805 encapsulation.

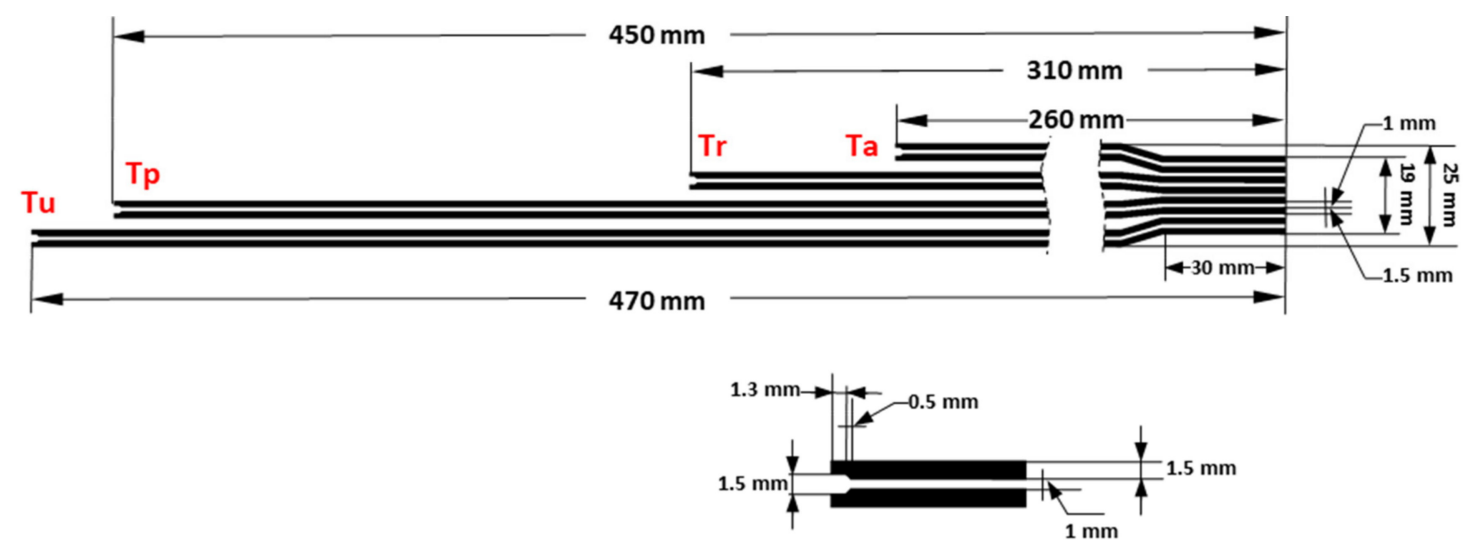

Figure 2. Multisensor dimensions. The top of the figure shows the overall dimensions, and the dimensions of the temperature sensor zone are shown at the bottom.

The support where the sensors are located must be a flexible material, such as cotton textile, PU, or PDMS, which are gas-permeable and biocompatible. Cotton textiles for medical uses are widely used. The PU film has perfect characteristics for its use in medical applications: breathability, elasticity, and formability. The most important characteristic for application as a dressing is breathability and, at the same time, the ability to keep the covered area dry. PDMS is recommended for laboratory experiments and medical research that require a gas-permeable and liquid-impermeable membrane.

Three PU films and one PDMS film have been used as substrates to define which provides the best results, and later they will be validated in cotton textiles. Table 4 shows the main characteristics of the PU films used: The EU50 and EU94DS were from DelStar Technologies, Inc. (Middletown, DE, USA), the SK81SS + 06 was from Novotex Italiana SpA (Gaggiano, MI, Italy), and the film PDMS SSPM823-040-12 was from SSP, Inc. (Ballston Spa, NY, USA). 
Table 4. Characteristics of the films.

\begin{tabular}{ccccc}
\hline & $\begin{array}{c}\text { DelStar } \\
\text { EU50 }\end{array}$ & $\begin{array}{c}\text { DelStar } \\
\text { EU94DS }\end{array}$ & $\begin{array}{c}\text { Novotex } \\
\text { SK81SS+06 }\end{array}$ & PDMS \\
\hline Thickness $(\mu \mathrm{m})$ & 50 & 80 & 25 & 100 \\
Weight $\left(\mathrm{g} / \mathrm{m}^{3}\right)$ & 55 & 94 & 1.20 & 1.12 \\
MVTR upright $\left.^{2} / \mathrm{m}^{2} / 24 \mathrm{~h}\right) 37^{\circ} \mathrm{C}$ & 700 & 400 & 441 & - \\
Tensile Strength MD ${ }^{* *}(\mathrm{gf} / \mathrm{cm})$ & 1200 & 3000 & 3610 & - \\
Elongation at break MD ${ }^{* *}(\%)$ & 1000 & 700 & 511 & 570 \\
${ }^{*}$ Moisture vapor transmission rate $(\mathrm{MVTR}) .{ }^{* *}$ Machine direction $(\mathrm{MD})$. & &
\end{tabular}

To print the conductive tracks on the substrate, which allow the electrical connection between the sensor and the connector, conductive silver inks (Table 5) have been screenprinted with two key features: elasticity and flexibility. PE873 from DuPont (Wilmington, DE, USA) and IPC-603X from Inkron (Kutojantie, Espoo, Finland), both with good compatibility with polymeric substrates, have been used. Neither manufacturer specifies their degree of biocompatibility.

Table 5. Characteristics of the silver inks.

\begin{tabular}{|c|c|c|}
\hline & $\begin{array}{l}\text { DUPONT } \\
\text { PE873 }\end{array}$ & $\begin{array}{l}\text { INKRON } \\
\text { IPC-603X }\end{array}$ \\
\hline Sheet resistivity $(\mathrm{m} \Omega / \mathrm{sq} / \mathrm{mil})$ & $<75$ & $<15$ \\
\hline Solids (\%) & $60-65$ & 100 \\
\hline Viscosity (Pas) & $50-80 @ 0.2 \mathrm{~s}^{-1}$ & $16 @ 0.25 \mathrm{~s}^{-1}$ \\
\hline Screens polyester (threads/inch) & $120-77$ & \\
\hline Curing & $160^{\circ} \mathrm{C}-10 \mathrm{~min}$ & $130^{\circ} \mathrm{C}-15 \mathrm{~min}$ \\
\hline Properties & $\begin{array}{ll}\text { - } & \text { Stretchable } \\
\text { - } & \text { Flexible } \\
\text { - } & \text { Washable with } \\
& \text { encapsulation }\end{array}$ & $\begin{array}{ll}\text { - } & \text { High stretchability } \\
\text { - } & \text { Flexible }\end{array}$ \\
\hline
\end{tabular}

\subsection{Electronic System}

Multisensor temperature measurements were carried out by an electronic system based on a microcontroller (Figure A1). The detailed circuit diagram is shown in Figure A2. It is a standalone system based on an ultralow-consumption 32-bit ARM Cortex STM32L151RB from STMicroelectronics (Geneva, Switzerland). Each of the four NTC sensors was excited by a $3 \mathrm{~V}$ voltage through a series resistance in a resistive divider configuration. Voltage was digitized in a 12-bit resolution ratiometric conversion (one sample per second for real-time measurements), converted to temperature, and stored in memory (one measurement per minute). Additionally, external temperature and humidity were recorded with an integrated Si7021 sensor from Silicon Laboratories Inc. (Austin, TX, USA). Temperatures were stored in an external flash memory using the serial peripheral interface (SPI) protocol.

The temperature measurement mode, the operating mode of the electronic system and its electrical characteristics, and the software used are shown in Appendix A.

\subsection{Manufacturing}

The manufacturing technology used was based on thick-film screen-printing technology. The screen-printing process consists of forcing pastes of different characteristics on a substrate through screens using scrapers. The openings in the screen define the pattern to be printed on the substrate. The final thickness of the pastes can be adjusted by varying the thickness of the screens.

When screen-printing technology is used, it is necessary to make frames with a mesh for the design. The screen for the conductive tracks was made of 230 PET 1500 90/23048 mesh polyester material from Sefar (Thal, Switzerland). To transfer the pattern to the 
screen mesh, a UV Dirasol 132 film from Fujifilm (Minato, Japan) was used. The final thickness of the screen was $74 \mu \mathrm{m}$ for the conductive designs screen. The pattern was transferred to the screen using an UV IC-5000 light source from BCB (Tarrasa, Spain).

Printing was carried out by using an EKRA E2XL screen printer from ASYS Group (Dornstadt, Germany) with a shore $75^{\circ}$ hardness squeegee, $60^{\circ}$ squeegee angle, $1 \mathrm{~mm}$ of snap-off, 3.5 bar of force, and a speed of $100 \mathrm{~mm} / \mathrm{s}$. Figure 3 shows the transferred pattern in each frame for printing multiple units at once.

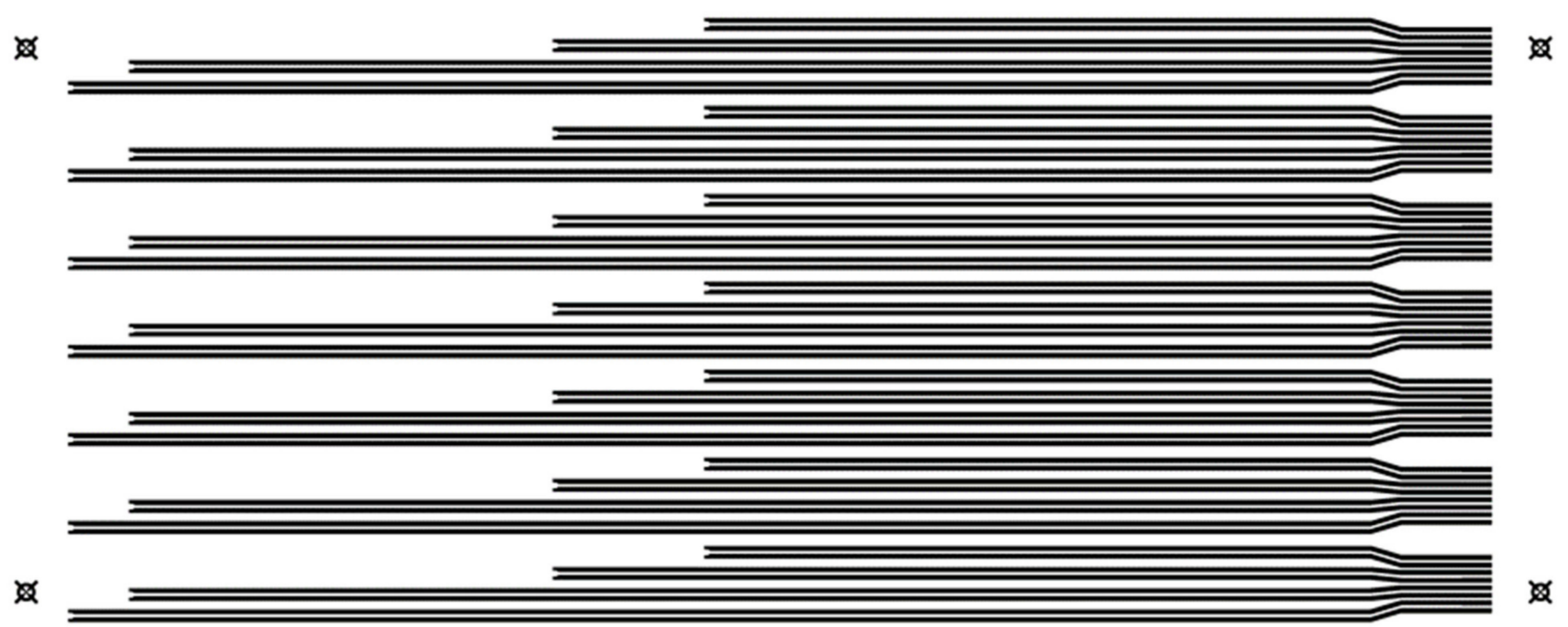

Figure 3. Pattern transferred to the printing screen. An $80 \times 65 \mathrm{~cm}$ frame was used, so seven identical multi-sensors were included.

After the deposition of inks, they were cured in a FED-115 air oven from BINDER (Tuttlingen, Germany) at $130{ }^{\circ} \mathrm{C}$ for $15 \mathrm{~min}$ using the same curing characteristics for both inks. Although some manufacturers recommend curing at higher temperatures, lower temperatures can be used with an increase of the cure time. In this case, it was done in this way to avoid the film deterioration during heating, since the typical melting point for PU films is $150{ }^{\circ} \mathrm{C}$. The final result is shown in Figure 4 .

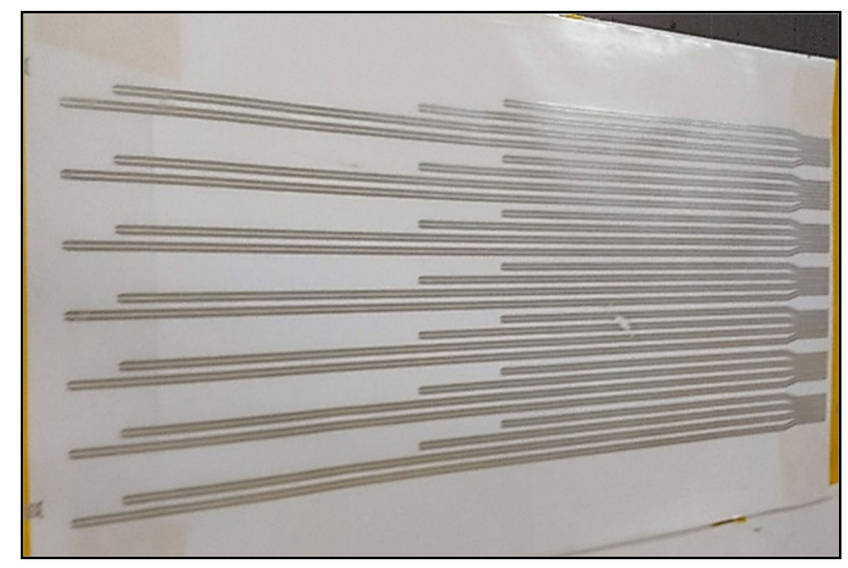

Figure 4. Pattern screen-printed with conductive silver ink on the polyurethane substrate.

The PU film's second layer was heat-sealed on the first layer with a DCH-100 thermal press from Microtec (Valencia, Spain) at $130{ }^{\circ} \mathrm{C}$ for $60 \mathrm{~s}$.

NTC thermistor welding on the PU has been a critical point, since the typical melting point is $150{ }^{\circ} \mathrm{C}$, as mentioned. For this reason, a soldering study, which is detailed in Section 3.4, was carried out. 
The NTC thermistors were covered with a thin layer of PDMS SYLGARD 184 from Sigma-Aldrich (St. Louis, MO, USA), deposited as a drop to avoid direct contact on the skin. On the other hand, PDMS provides consistency to the solder, hindering possible shear failures when the stretching of the base film occurs. Figure 5 shows the result of this process. Although PDMS thermal conductivity was very low $(0.2 \mathrm{~W} / \mathrm{m} \cdot \mathrm{K})$, and therefore there was some inherent thermal inertia to the NTC-PDMS block, it was not critical since the measurement was carried out every $60 \mathrm{~s}$, a long enough period to stabilize the temperature in the NTC-PDMS block. Furthermore, the goal of the electrode was to measure temperature increases, rather than to accurately measure the temperature at the operation point.

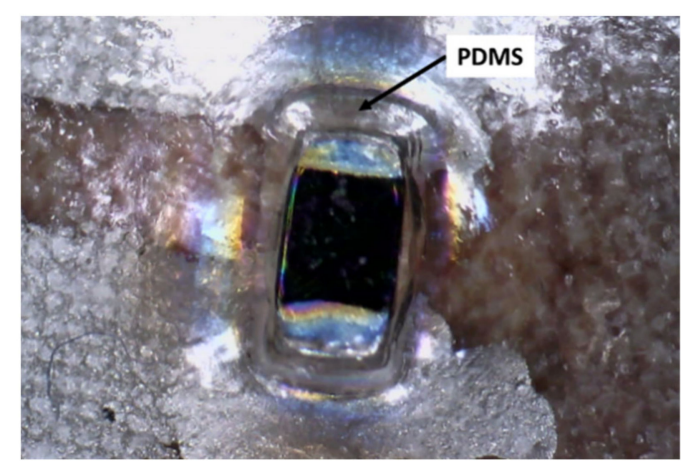

Figure 5. PDMS drop used to isolate the sensor from skin contact.

Clincher flex connectors from Amphenol Corporation (Wallingford, CT, USA) were used to connect the electrodes with the measurement equipment, since they allow close contact between the conductive tracks and the connector by pressure. With this configuration, the final prototypes shown in Figure A6 weredeveloped

\subsection{Measurements}

Resistance measurements were made with a Fluke 8845A multimeter from Fluke Corp. (Everett, WA, USA).

3D profilometry was measured with a Profilm3D profilometer from Filmetrics Inc. (San Diego, CA, USA) with a Nikon CF IC Epi Plan $\times 20$ objective.

For the tensile test on PU films, a 3400 single-column equipment from Instron (Norwood, MA, USA) was used to determine the behavior of materials under axial stretching loads (up to $5000 \mathrm{~N}$ ). The sample length increased between $1 \%$ and $10 \%$ of its nominal length, and its resistance was measured with the Fluke 8845A multimeter (Figures 6 and 7).

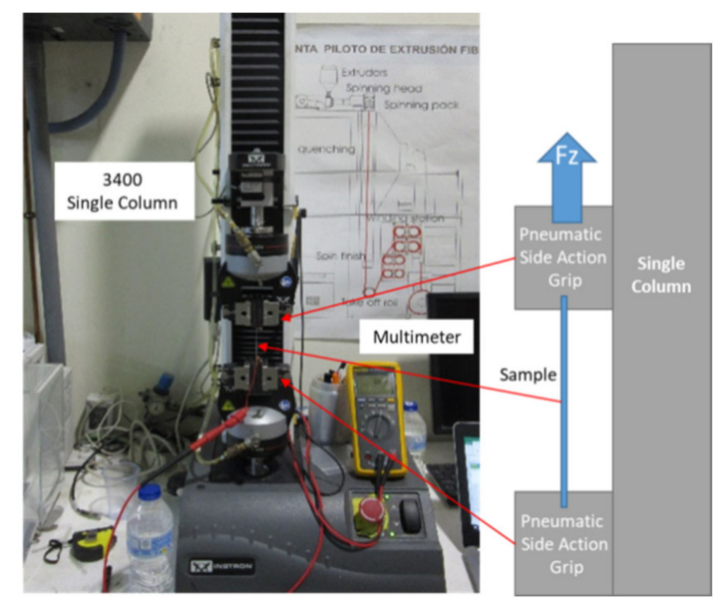

Figure 6. Experimental setup used for applying axial force and acquiring data during the electrode characterization. 


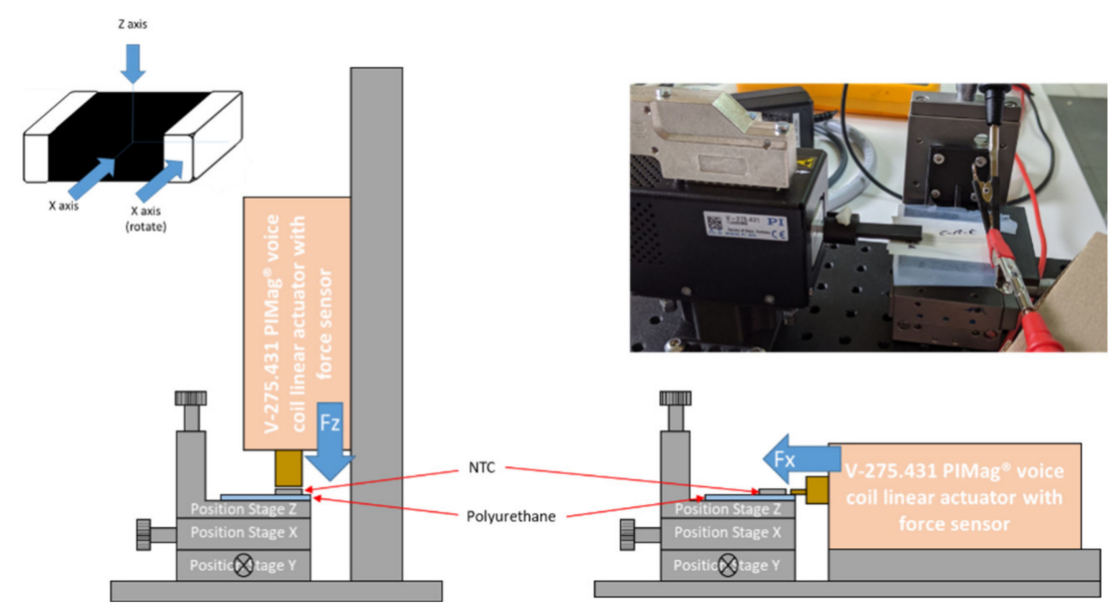

Figure 7. Experimental setup used for applying the $\mathrm{Z}$ and $\mathrm{X}$ forces (and $\mathrm{X}$ force rotation) and acquiring data during the electrode characterization.

To measure the shear strength of welds, the V-275.431 PIMag voice-coil linear actuator with force sensor from Physik Instrument (PI) GmbH \& Co. KG (Karlsruhe, Germany) was used.

\section{Results and Discussion}

\subsection{Study of the Conductive Inks on Films}

The surface characteristics of PDMS made it difficult to print conductive inks on this film. To improve printing, different surface treatments had to be used to improve the surface tension of PDMS, such as a treatment with 30\% sulfuric acid or a corona treatment. Despite obtaining improvements, it was decided not to use this substrate since the final print was not adequate (Figure 8).

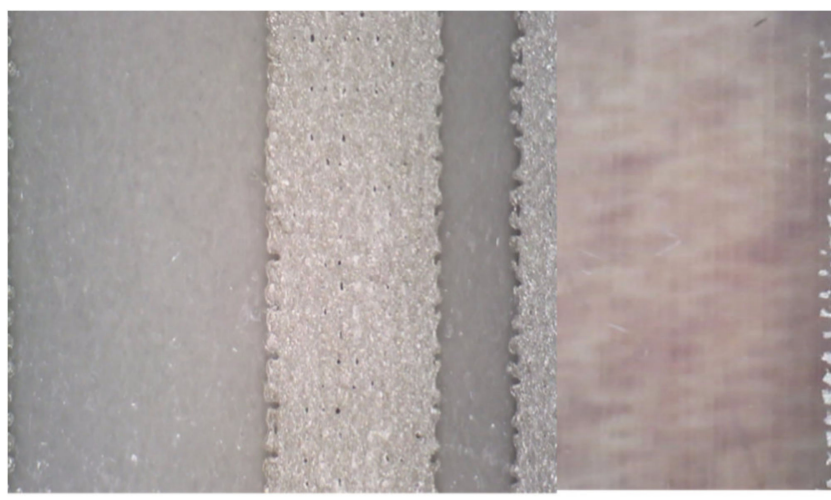

a)

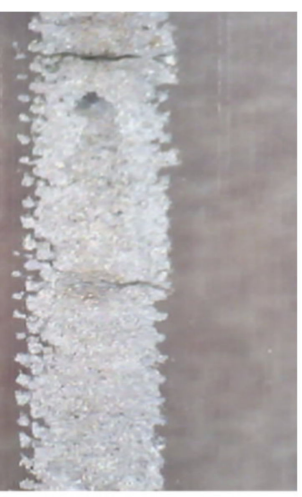

b)

Figure 8. (a) Printing of the conductive silver ink on polyurethane; (b) printing defects of a conductive line on PDMS.

To calculate the average thickness of both inks, a resistance pattern of $15 \times 3 \mathrm{~mm}$ was screen-printed on thermosetting PET film, resulting in an average layer thickness of $1.2 \mu \mathrm{m}$ for DuPont PE873 and $7 \mu \mathrm{m}$ for Inkron IPC-603X (Figure 9). 


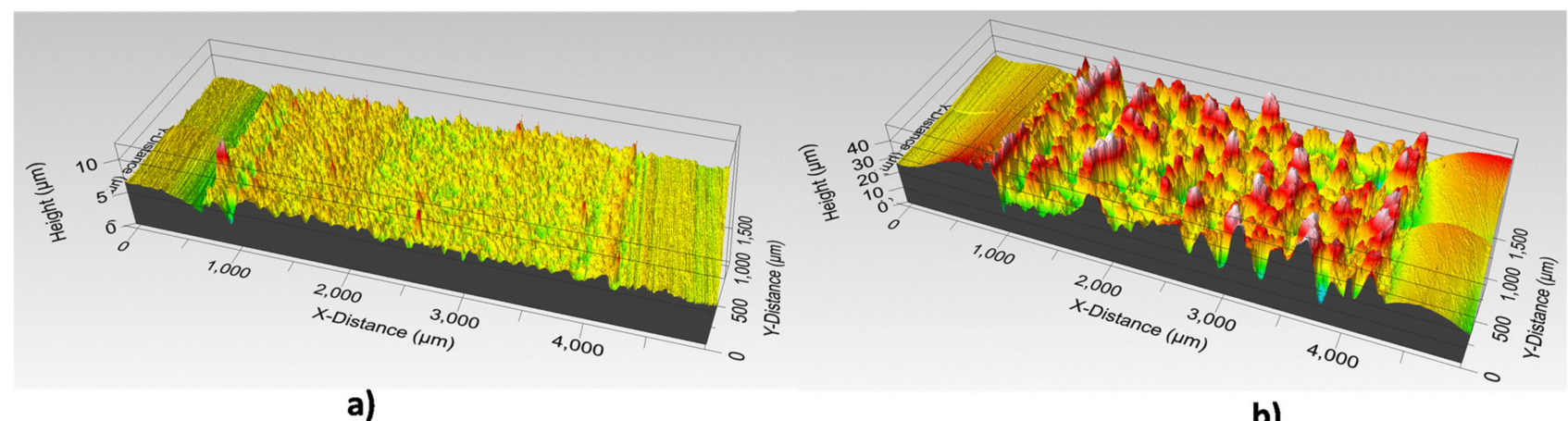

a)

b)

Figure 9. 3D profilometry of a section of the pattern printed with (a) DuPont PE873 ink and (b) Inkron IPC-603X on the PET thermosetting substrate.

Conductive layer thickness before drying can be calculated using Equation (1):

$$
T_{b d}=\left(T_{S} \cdot A_{s}\right)+T_{f}
$$

where $T_{b d}$ is the thickness of the conductor before drying, $T_{S}$ is the thickness of the screen, $A_{S}$ is the open area of the screen, and $T_{f}$ is the thickness of the photosensitive film. The values used were from the display data sheet used for the 230 mesh polyester material conductors (PET 1500 90/230-48 from Sefar) and the UV Dirasol 132 film from Fujifilm. The value obtained for $T_{b d}$ was $21.75 \mu \mathrm{m}\left(T_{S}=71 \mu \mathrm{m}, A_{S}=25 \%\right.$, and $\left.T_{f}=4 \mu \mathrm{m}\right)$.

$T_{b d}$ is reduced after drying according to the percentage of solid content and the type of ink solvent. The reduction after drying was $94.5 \%$ for the DuPont ink and $67.8 \%$ for the Inkron ink.

Then, the actual resistivity value was calculated and compared with the sheet resistivity provided by the manufacturer.

Equations (2) and (3) make the comparison possible:

$$
\begin{gathered}
R_{S}=\varrho \frac{L}{t \cdot W} \rightarrow \varrho=\frac{R_{S} \cdot t \cdot W}{L} \\
\varrho_{\text {Sheet }}=\frac{\varrho}{25 \mu \mathrm{m}}
\end{gathered}
$$

where $R_{S}$ is the resistance of the sample (1.1 $\Omega$ in the case of DuPont ink and $0.35 \Omega$ in the case of Inkron ink), $\rho$ is the resistivity, $\varrho_{\text {sheet }}$ is the manufacturer's sheet resistivity, $t$ is the layer thickness, $\mathrm{L}$ is the length, and $\mathrm{W}$ is the resistance width. The value of $25 \mu \mathrm{m}$ is the print thickness used by manufacturers to specify the resistivity of the sheet.

Therefore, for DuPont PE873 ink, the resulting sheet resistivity was $7.5 \mathrm{~m} \Omega / \mathrm{sq} / \mathrm{mil}$ (according to the manufacturer, $<75 \mathrm{~m} \Omega / \mathrm{sq} / \mathrm{mil}$ ), and for the Inkron IPC-603X ink, the resistance of the sheet resistivity was $16 \mathrm{~m} \Omega / \mathrm{sq} / \mathrm{mil}$ (according to the manufacturer, $<15 \mathrm{~m} \Omega / \mathrm{sq} / \mathrm{mil})$.

\subsection{Study of the Polyurethane Films on Fabrics}

To test the elongation effect on screen-printed conductive inks printed on PU and PDMS films, a test was carried out with patterns of different widths. The test checked the pattern value according to the percentage of elongation. In the case of PDMS, the results were not conclusive, since the printing of the conductive inks on this film was not perfect, as previously mentioned, and when the test was carried out, the inks came off the substrate.

For carrying out the test on the traction equipment, specific test samples were designed and printed with the dimensions shown in Figure 10. The equipment was programmed to stretch the samples up to $10 \mathrm{~mm}$, in intervals of $1 \mathrm{~mm}$ and with stops of $25 \mathrm{~s}$, to carry out the electrical-resistance measurements. 


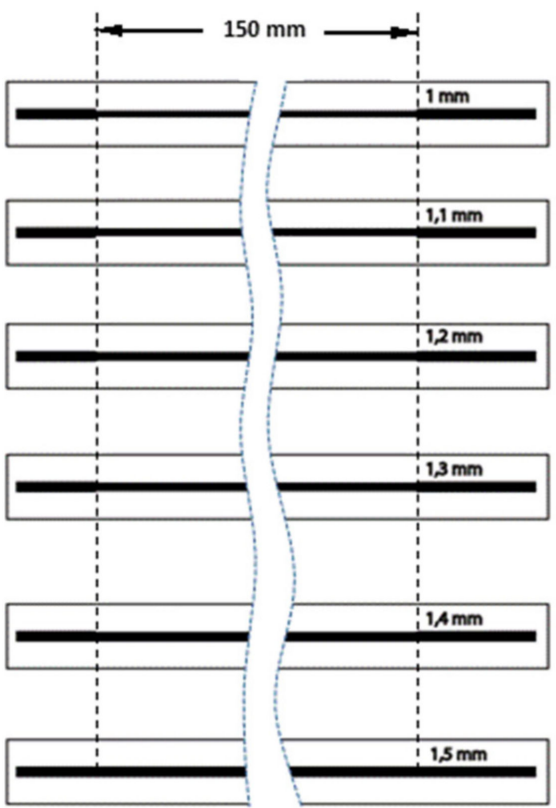

Figure 10. Dimensions of the pattern used to determine the parameters of elongation of inks and base films.

Figures A7-A12 in Appendix A show the resistance variation according to the elongation of each pattern of the screen-printed inks on the different substrates.

Figure 11 shows the percentage variation of the resistance value according to the percentage elongation for the $1.5 \mathrm{~mm}$-wide pattern, since it was the one used for the sensor design. The most suitable combination to obtain a reduced variation was the Inkron IPC-603X ink with the DelStar EU94DS substrate, as can be observed in the graph.

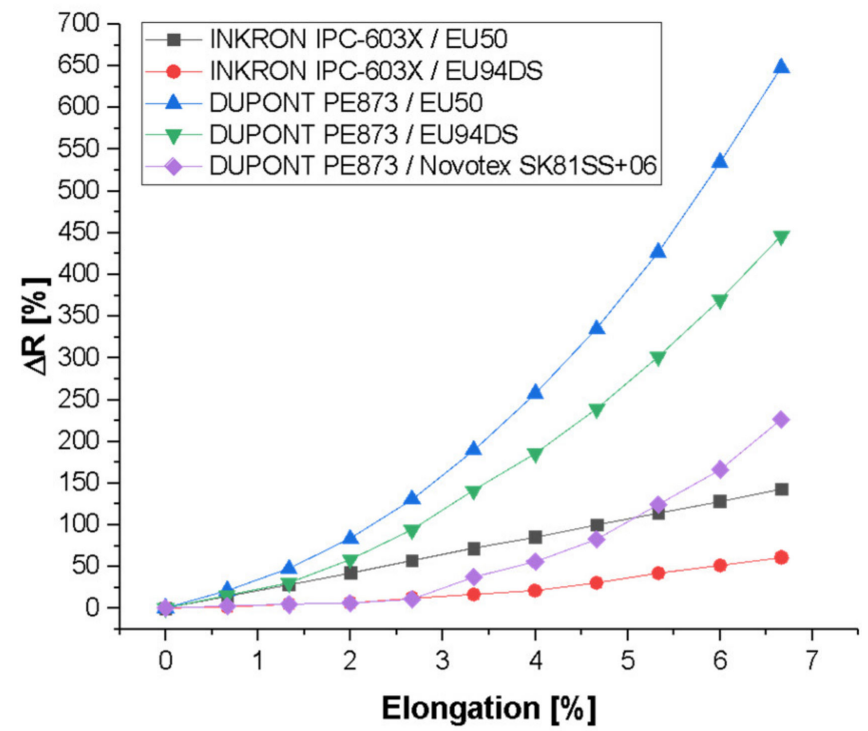

Figure 11. Percentage variation of the resistance value according to the percentage elongation for the $1.5 \mathrm{~mm}$-wide pattern.

\subsection{Study of the Conductive Tracks' Resistance}

The conductive tracks' resistance after printing was $39.1 \pm 0.2 \Omega$ for $\mathrm{Tu}, 34.3 \pm 0.5 \Omega$ for Tp, $23.2 \pm 0.4 \Omega$ for $\mathrm{Tr}$, and $21.0 \pm 0.5 \Omega$ for Ta. With these track resistance values; the substrate would have to be $133 \%$ longer to cause a variation of $0.5{ }^{\circ} \mathrm{C}$ in the measurement for the selected NTC thermistor. 


\subsection{Study of NTC Soldering}

NTC solder with Inkron IPC-603X ink on a DelStar EU94DS substrate has been studied. The weld must not exceed $150{ }^{\circ} \mathrm{C}$ due to the PU melting point. This temperature limits the type of solder pastes that can be used, so work has been done with:

- The same silver ink (Inkron IPC-603X) that was used in the conductive tracks acting as a solder paste, although in this case it would act as a conductive adhesive. Curing was carried out at $130{ }^{\circ} \mathrm{C}$. The advantage of soldering with conductive ink is the ability to use the same temperature in the conductor-manufacturing process, and in soldering, the disadvantage is that the ink viscosity is low, and it is difficult to place on pads with stencils.

- An anisotropic conductive adhesive that allows a first curing by long-wave ultraviolet rays (UVAs) to block the solder, and subsequently perform a low-temperature thermal curing. The paste used was DELO MONOPOX AC245 from DELO Adhesives (Windach, Germany). This paste requires a first UVA curing, between $320 \mathrm{~nm}$ and $400 \mathrm{~nm}$ from $1 \mathrm{~s}$ to $5 \mathrm{~s}$, and then a thermal curing between $80^{\circ} \mathrm{C}$ and $150{ }^{\circ} \mathrm{C}$ for $30 \mathrm{~min}$ and $10 \mathrm{~min}$, respectively. In this case, a Ncure-Lab/Static $120 \mathrm{UV}$ oven from EneMaq (Barcelona, Spain) with $0.5 \mathrm{~J} / \mathrm{cm}^{2}$ and a FED-115 air oven from BINDER were used at $130{ }^{\circ} \mathrm{C}$ for $15 \mathrm{~min}$. The advantages of the anisotropic solder paste are the proper viscosity and that the paste can be placed with less precision on the pads, while the disadvantage is that it requires two curing processes, $\mathrm{UV}$ and thermal.

- An NC-SMQ80/1E paste (52In/48Sn) from Indium Corp. (Clinton, NY, USA) with a melting point of $118^{\circ} \mathrm{C}$. The temperature peak was set at $135^{\circ} \mathrm{C}$ for $110 \mathrm{~s}$. This is a solder paste with a very low melting point, but with the drawback of not presenting $\mathrm{Ag}$ in its composition, making it difficult to solder with the silver ink.

- A Voltera T4/T5 (57.6Bi/42Sn/0.4Ag) from Voltera (Kitchener, Canada) with a melting point of $138{ }^{\circ} \mathrm{C}$. The temperature peak was set at $145^{\circ} \mathrm{C}$ for $90 \mathrm{~s}$. This solder paste contains silver, and although its melting point is low, it was too close to the $150{ }^{\circ} \mathrm{C}$ limit imposed.

Two types of footprints were designed, one with the recommended size for solder reflow and the other for solder wave based on an encapsulation size of 0805 (Figure 12). All pastes and adhesives were printed on the track pads using a $250 \mu \mathrm{m}$-thick stainless-steel stencil with a print speed of $20 \mathrm{~mm} / \mathrm{s}$ and a squeegee pressure of $0.02 \mathrm{~kg} / \mathrm{mm}$ of blade length. Figures 13 and 14 show the soldering results.

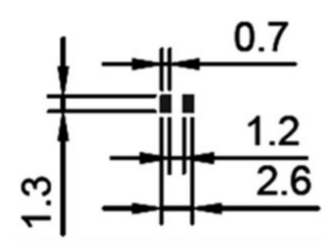

a)
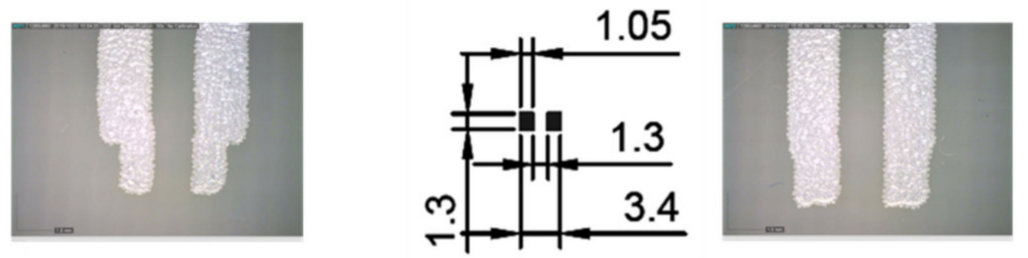

b)

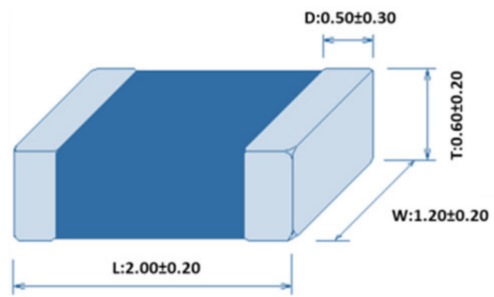

c)

Figure 12. (a) The 0805 solder reflow footprint, (b) the 0805 wave solder footprint and (c) the 0805 package (mm). 


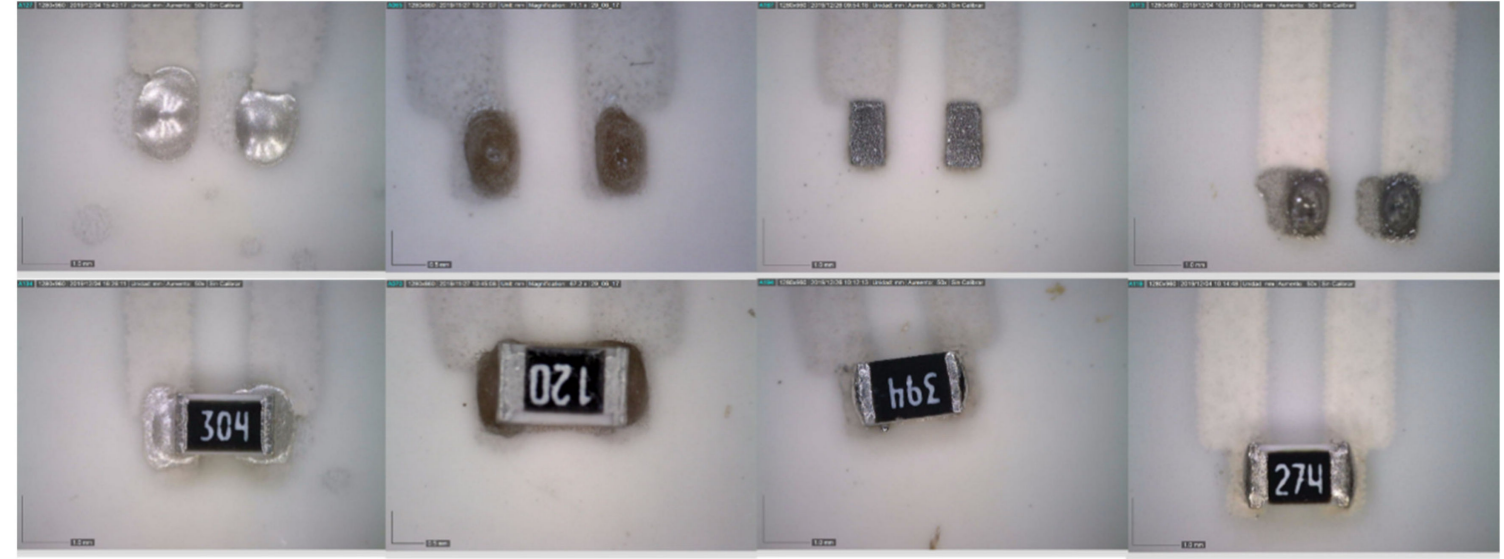

a) c) d)

Figure 13. Stencil printing of pastes/adhesives on solder reflow footprint. Above: after printing; below: after temperature curing. (a) Inkron IPC-603X, (b) DELO MONOPOX AC245, (c) NC-SMQ80/1E, and (d) Voltera T4/T5.

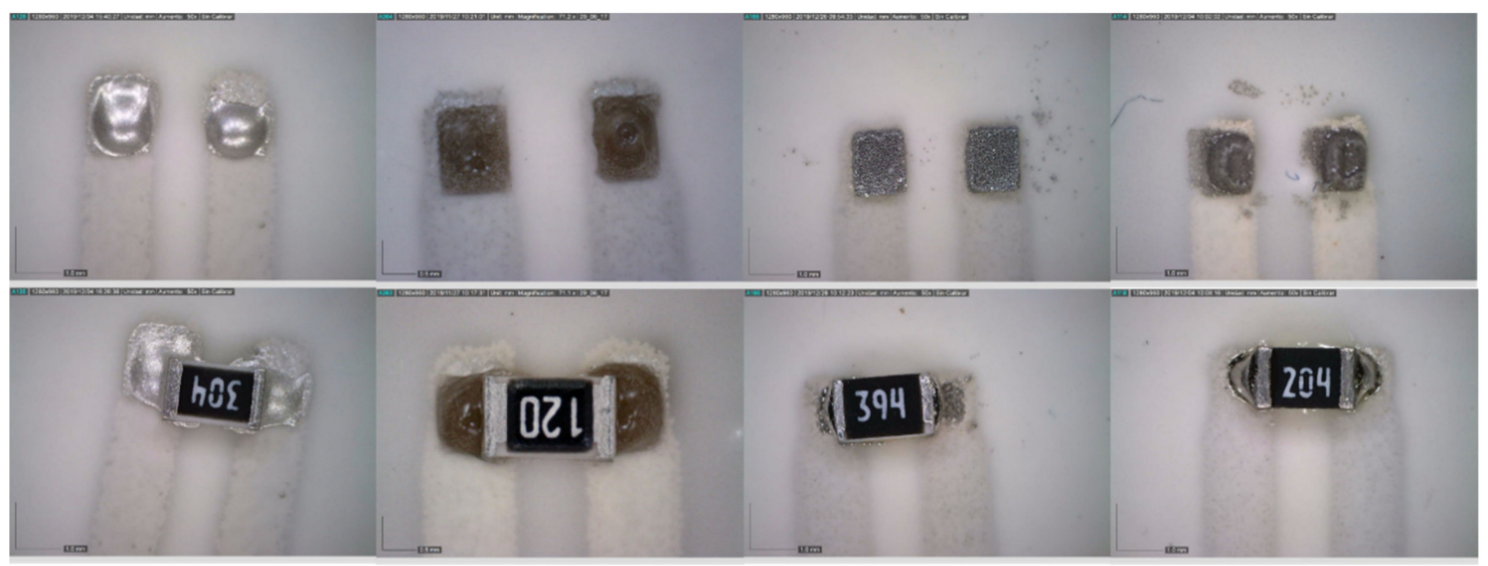

a)

b)

c)

d)

Figure 14. Stencil printing of pastes/adhesives on wave reflow footprint. Above: after printing; below: after temperature curing. (a) Inkron IPC-603X, (b) DELO MONOPOX AC245, (c) NC-SMQ80/1E, and (d) Voltera T4/T5.

After printing and curing of the pastes, continuity measurements were made to check the correct soldering. Table 6 shows the percentages of correct solders.

Table 6. Percentage of correct package soldered with stencil printing technique.

\begin{tabular}{ccc}
\hline & Solder Reflow Footprint & Wave Solder Footprint \\
\hline INKRON IPC-603X & $57.1 \%$ & $57.1 \%$ \\
DELO MONOPOX AC245 & $71.4 \%$ & $28.5 \%$ \\
NC-SMQ80/1E & $100 \%$ & $100 \%$ \\
VOLTERA T4/T5 & $71.4 \%$ & $57.1 \%$ \\
\hline
\end{tabular}

With respect to the Inkron IPC-603X ink, the screen-printing technique was also used, since this ink is specific to this technology (Figure 15). In this case, percentages reached $100 \%$ and $85.7 \%$ for the solder reflow footprint and the wave solder footprint, respectively. 


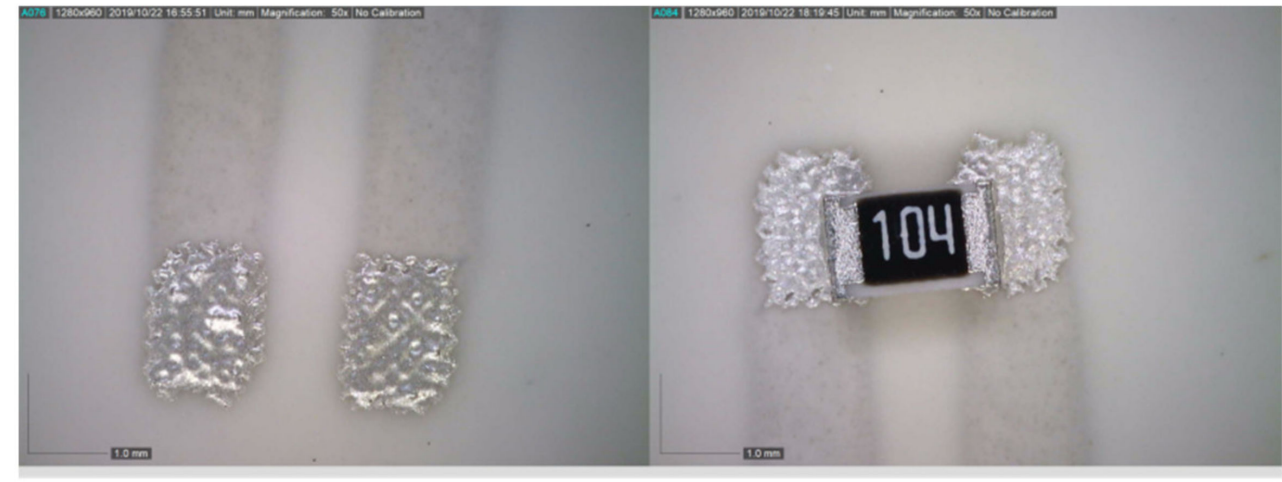

a)

b)

Figure 15. Screen printing of the Inkron IPC-603X on wave reflow footprint: (a) after printing; and (b) after temperature curing.

Figure 16 shows the appearance of the solder from the back of the PU. It was observed how the NC-SMQ80/1E paste had a very good integration with the conductor silver.

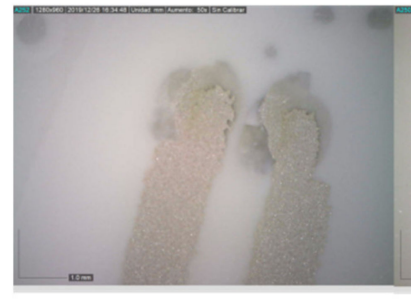

a) b)

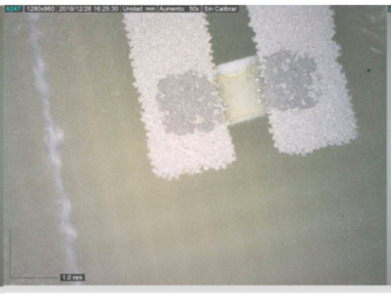

c)

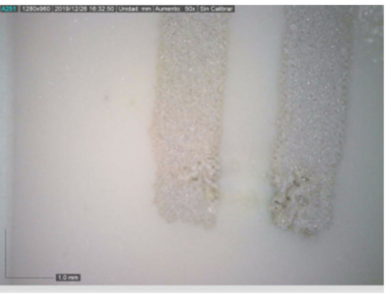

d)

Figure 16. Solder view from the back of the polyurethane. (a) Inkron IPC-603X, (b) DELO MONOPOX AC245, (c) NCSMQ80/1E, and (d) VOLTERA T4/T5.

Once welded and protected with PDMS, the electrodes with the NTC thermistors must withstand a minimum pressure of $10 \mathrm{mmHg}(1333.22 \mathrm{~Pa})$ and a maximum of $40 \mathrm{mmHg}$ (5332.9 Pa) by the compression bandage [21]. This means that in the 0805 package, a force of $0.015 \mathrm{~N}$ was on the $\mathrm{Z}$ axis, and a force of $0.006 \mathrm{~N}$ was on the $\mathrm{X}$ axis.

Table 7 shows the shear-strength tests performed on the $Z, X$, and $X$ (rotation) axes for both types of footprint. Figure 17 shows the effects of the shear force on the solder reflow footprint on the $\mathrm{X}$ axis and $\mathrm{X}$ axis (rotation). It was observed that the break occurred simultaneously with the silver ink of the conductive tracks in the case of the NC-SMQ80/1E paste. This effect also was detected in the Voltera T4/T5 ink, although minor in the case of the $X$ axis.

Table 7. Maximum force $(\mathrm{N})$ applied on the axis.

\begin{tabular}{ccccccc}
\hline & \multicolumn{2}{c}{ Z axis } & \multicolumn{2}{c}{ X axis } & \multicolumn{2}{c}{ X axis (Rotation) } \\
\hline & $\begin{array}{c}\text { Solder Reflow } \\
\text { Footprint }\end{array}$ & $\begin{array}{c}\text { Wave Solder } \\
\text { Footprint }\end{array}$ & $\begin{array}{c}\text { Solder Reflow } \\
\text { Footprint }\end{array}$ & $\begin{array}{c}\text { Wave Solder } \\
\text { Footprint }\end{array}$ & $\begin{array}{c}\text { Solder Reflow } \\
\text { Footprint }\end{array}$ & $\begin{array}{c}\text { Wave Solder } \\
\text { Footprint }\end{array}$ \\
\cline { 2 - 7 } INKRON IPC-603X & 10 & 10 & 0.304 & 0.809 & 0.433 & 1.247 \\
DELO MONOPOX & 10 & 0.01 & 0.787 & 0.001 & 0.377 & 0.001 \\
AC245 & 10 & 10 & 1.247 & 1.625 & 1.119 & 1.496 \\
NC-SMQ80/1E & 10 & 10 & 0.156 & 0.375 & 0.287 & 0.896 \\
VOLTERA T4/T5 & & & & & &
\end{tabular}




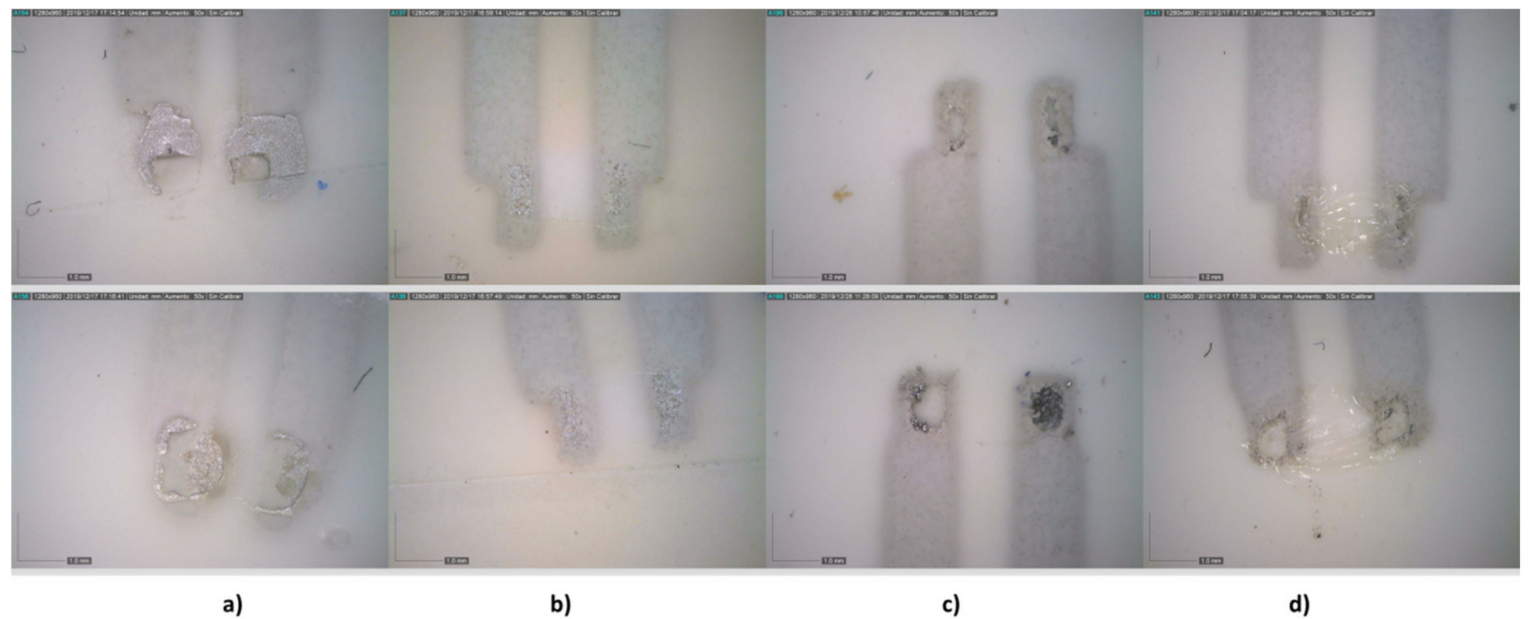

Figure 17. Effect of shear force on the solder reflow footprint: $X$ axis (above) and $X$ axis (rotation) (below). (a) Inkron IPC-603X, (b) DELO MONOPOX AC245, (c) NC-SMQ80/1E, and (d) Voltera T4/T5.

All results exceeded the needed values to withstand the pressure of the bandage, which was $0.015 \mathrm{~N}$ on the $\mathrm{Z}$ axis and $0.006 \mathrm{~N}$ on the $\mathrm{X}$ axis. However, the NC-SMQ80/1E paste significantly outperformed the rest in either case.

\subsection{Field Testing}

First, tests carried out in a healthy individual made it possible to verify the operation of the registration system. Once longitudinally separated (Figure A6, top), sensors were placed on healthy skin, ensuring good contact with the PDMS face. The NTC1 thermistor, the one with the longest connection, was located $3 \mathrm{~cm}$ from the ankle, leaving the others at different distances according to the length of the leg (Figure 18). Then, a minimally compressive bandage was applied, leaving the connection to the registration prototype out (Figure 19a). Finally, the system was fixed below the knee with a new padded bandage to protect the circuit and the leg (Figure 19b).

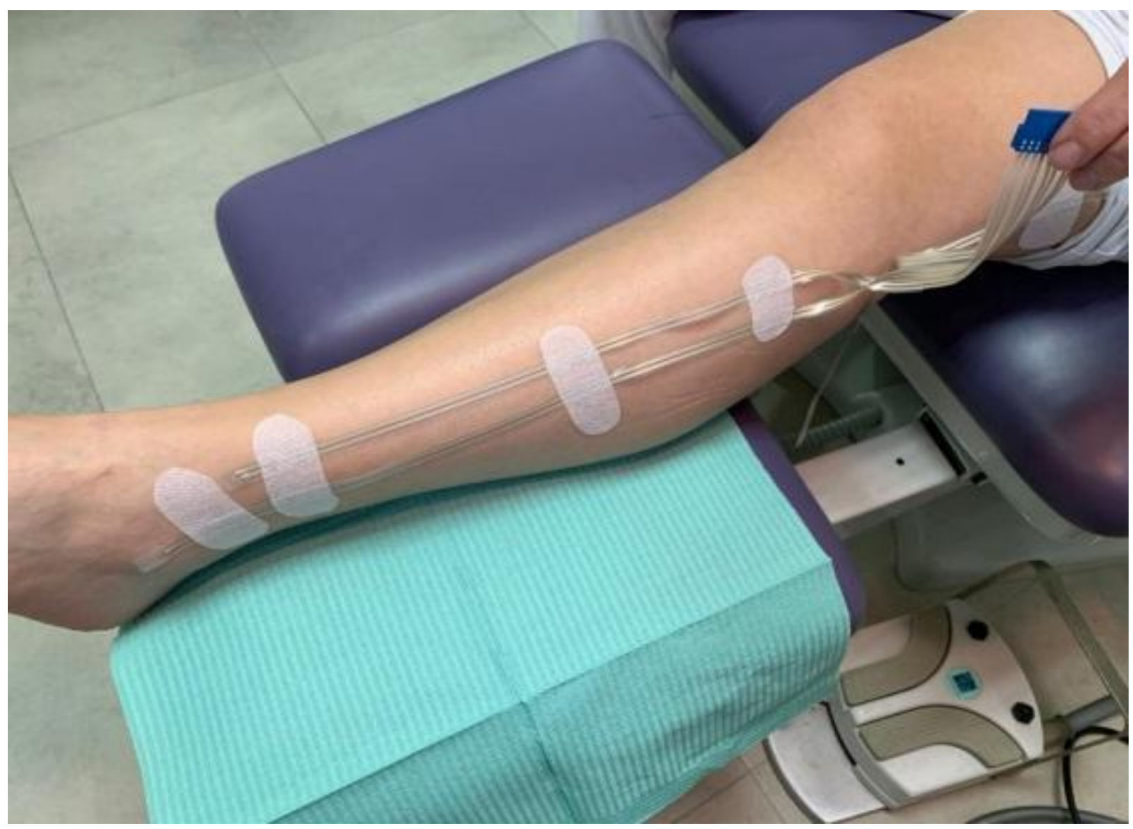

Figure 18. Placement of the system along the leg. 


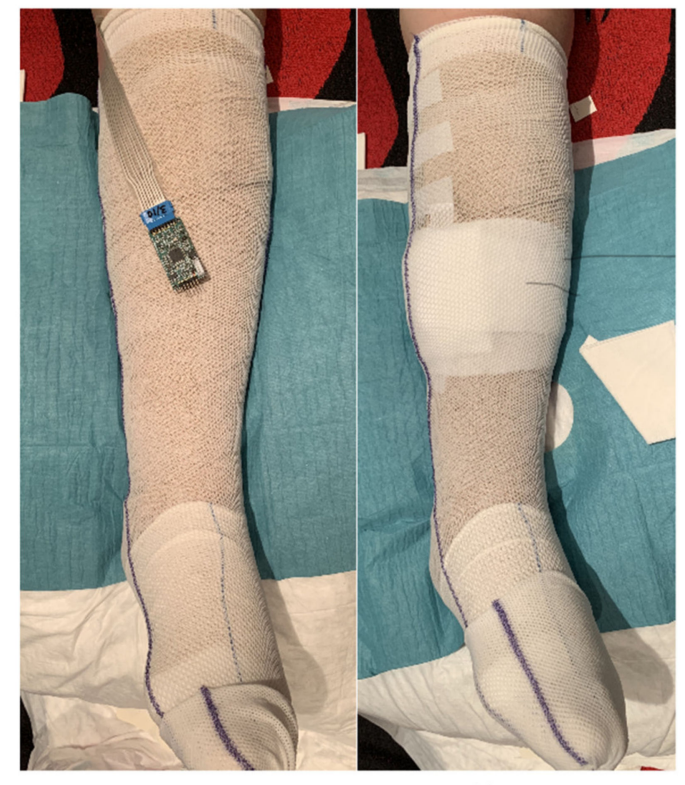

Figure 19. Placement of the system in the wound dressing. (a) Sensors applied under a finished bandage; (b) protection of the data acquisition system to avoid damaging the device and the patient during their activity.

Figure 20 shows the evolution of the four temperatures involved over a $24 \mathrm{~h}$ period. The temperatures of the sensors in contact with the skin underwent small variations throughout the day, being very stable in the night period (hours 14 to 22 in the series). The differences between them remained in a very small range.

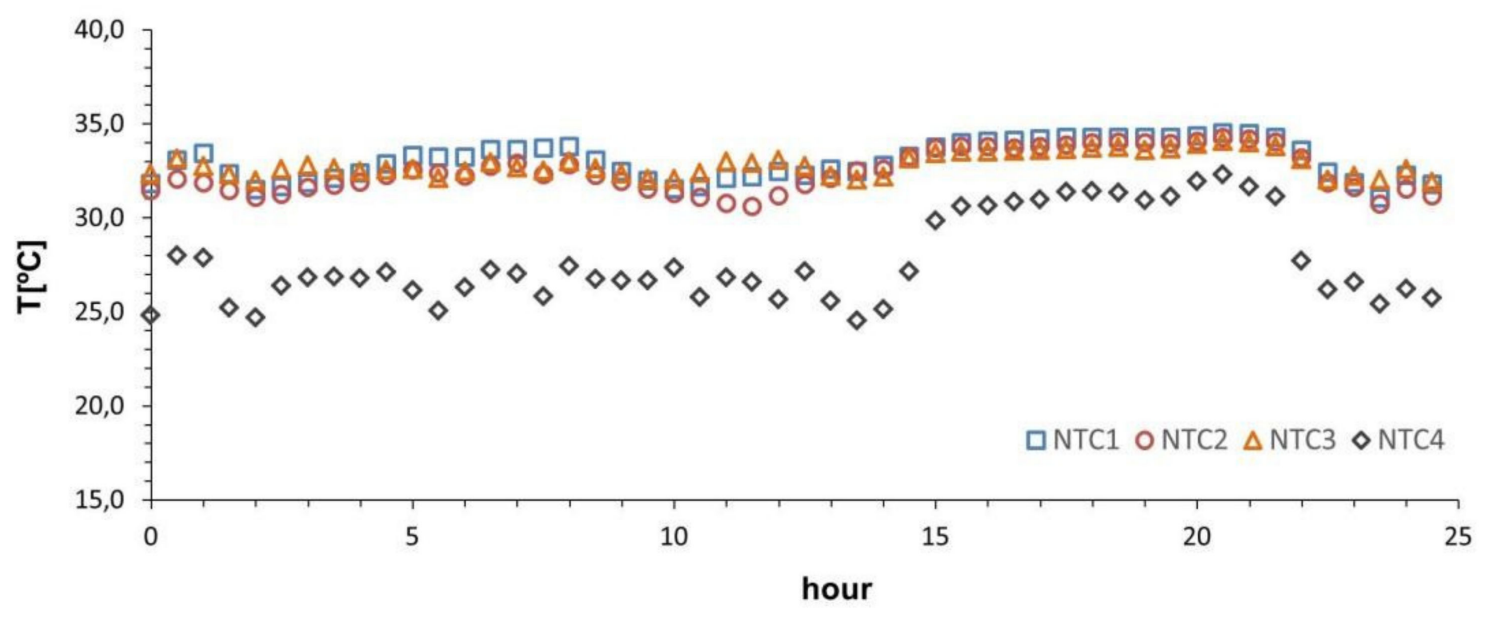

Figure 20. Temperature data recorded over a $24 \mathrm{~h}$ period. NTC1 = skin lesion, NTC2 = perilesional skin, NTC3 = healthy skin, and NTC4 = environmental.

Figure 20 shows the temperature behavior in each of the regions where a sensor was placed in a simulated wound on the intact skin of an investigator. As mentioned above, the fluctuations between the sensors were minimal. These differences may vary, depending on, among other things, the activity that was being carried out at that time, the position of the leg, or the type of clothing. Between 10:00 p.m. and 3:00 p.m., the activity was minimal. From 3:00 p.m. to 10:00 p.m., the researcher underwent more activity as part of the test. It was found that the temperature increase occurred in all the sensors, especially in the 
NTC4 (environmental). The temperature change of the NTC1 between 5:00 a.m. and 8:00 a.m. could be caused by the position and support of the limb during the last hours of sleep. On the other hand, the increase of this same NTC thermistor in the most active time slot may have been due to the friction of the sensor with the bandage produced by the movement. Therefore, taking the activity into account is essential during the data collection to determine the cause of possible anomalous data.

\section{Conclusions}

In the development phase of the NTC electrode with encapsulation 0805, it was proven that, from a technological point of view, the best option was the use of a DelStar EU94DS medical grade polyurethane substrate with Inkron IPC-603X silver ink in screen printing; using the NC-SMQ80/1E paste from Indium for welding.

The NTC device must be protected with a PDMS layer. This structure can withstand the stresses of the compression bandage, as well as the inherent stretching in the use of the electrodes during the data-acquisition phase in a patient, without breaks.

The developed electronic system has proven to be robust, low consumption, and comfortable for the patient, and it allows control of the data acquisition times, as well as the data dump for further study.

Field tests in a healthy individual verified the correct operation of the system, as well as the data acquisition over long periods of time without causing discomfort to the individual and without electrode breaks or data losses.

The study's next steps will consist of carrying out the necessary tests for cytotoxicity for contact with wounds, antimicrobials, measurements in patients, and the subsequent data treatment that will allow better monitoring of chronic wounds.

Author Contributions: Conceptualization, A.M.R.-C., J.T.-V., M.A.J.B. and A.C.F.; methodology, A.T.F.; software, A.C.F.; validation, A.G.I., A.T.F. and J.T.-V.; formal analysis, A.M.R.-C.; investigation, A.M.R.-C. and J.T.-V.; writing - original draft preparation, A.M.R.-C., J.T.-V. and A.C.F.; writingreview and editing, A.M.R.-C., J.T.-V., A.G.I., A.T.F., M.A.J.B. and A.C.F. All authors have read and agreed to the published version of the manuscript.

Funding: This research was supported by the Spanish Government/FEDER funds (RTI2018-100910B-C43) (MINECO/FEDER). The work presented also was funded by the Conselleria d'Economia Sostenible, Sectors Productius i Treball, through IVACE (Instituto Valenciano de Competitividad Empresarial). HYBRID II Project-Application No.: IMAMCI/2021/1.

Institutional Review Board Statement: Not applicable.

Informed Consent Statement: Not applicable.

Patents: The polyurethane screen-printing system presented in this work is in the process of receiving a Spanish patent (number P202030107).

Acknowledgments: The authors would like to thank the Intelligent Textiles and ICT Solutions research group of the Textile Industry Research Association (AITEX) for their involvement in the technical and logistical support to carry out this research project.

Conflicts of Interest: The authors declare no conflict of interest.

Ethical Statement: The subject involved in the application example of the device developed gave their informed consent for inclusion. The study was conducted in accordance with the Declaration of Helsinki, and the protocol was approved by the Ethics Committee of Universidad Católica de Valencia San Vicente Mártir with project code UCV/2019-2020/153. This project complies with the good practices of research ethics and all current regulations concerning the protection of personal data.

\section{Appendix A}

Appendix A.1. Electronic System

To obtain the temperature from the NTC thermistor resistance, a third-degree polynomial approximation was used (Equation (A1)). $R_{T}$ is the temperature resistance $T$, and $R_{25}$ 
is the nominal resistance at $25^{\circ} \mathrm{C}$. For the NTC thermistor model used, NTCS0603E3104, $R_{T}=100 \mathrm{k} \Omega$, and the coefficients of the expression provided by the manufacturer are: $A=0.003354016, B=0.000248277, C=1.84 \times 10^{-6}$, and $D=-2.62 \times 10^{-8}$.

$$
T=\frac{1}{A+B \cdot \ln \left(\frac{R_{T}}{R_{25}}\right)+C \cdot \ln ^{2}\left(\frac{R_{T}}{R_{25}}\right)+D \cdot \ln ^{3}\left(\frac{R_{T}}{R_{25}}\right)}
$$

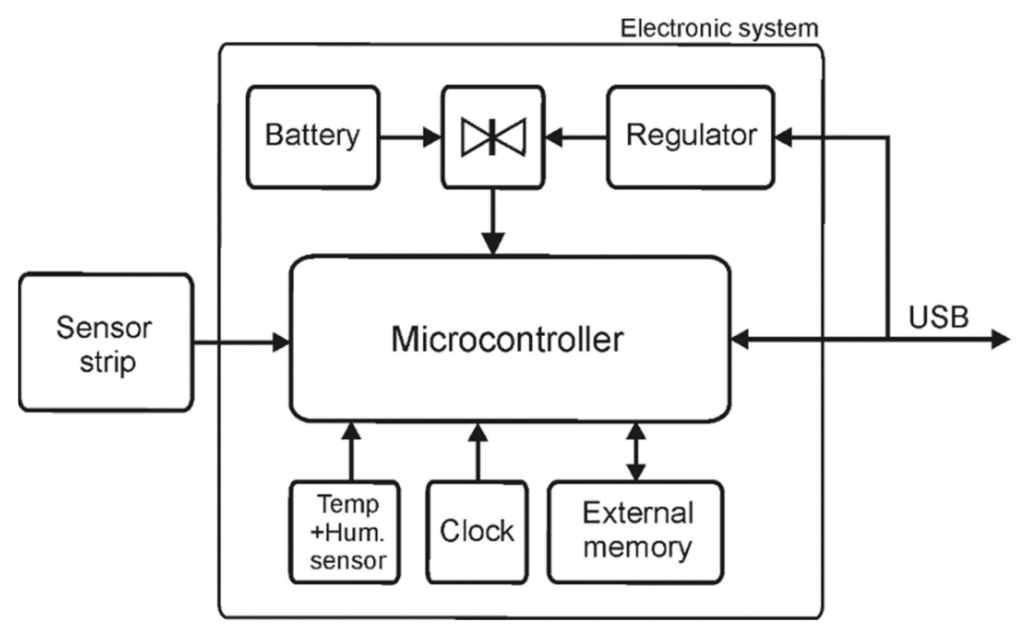

Figure A1. Block diagram of the electronic system.

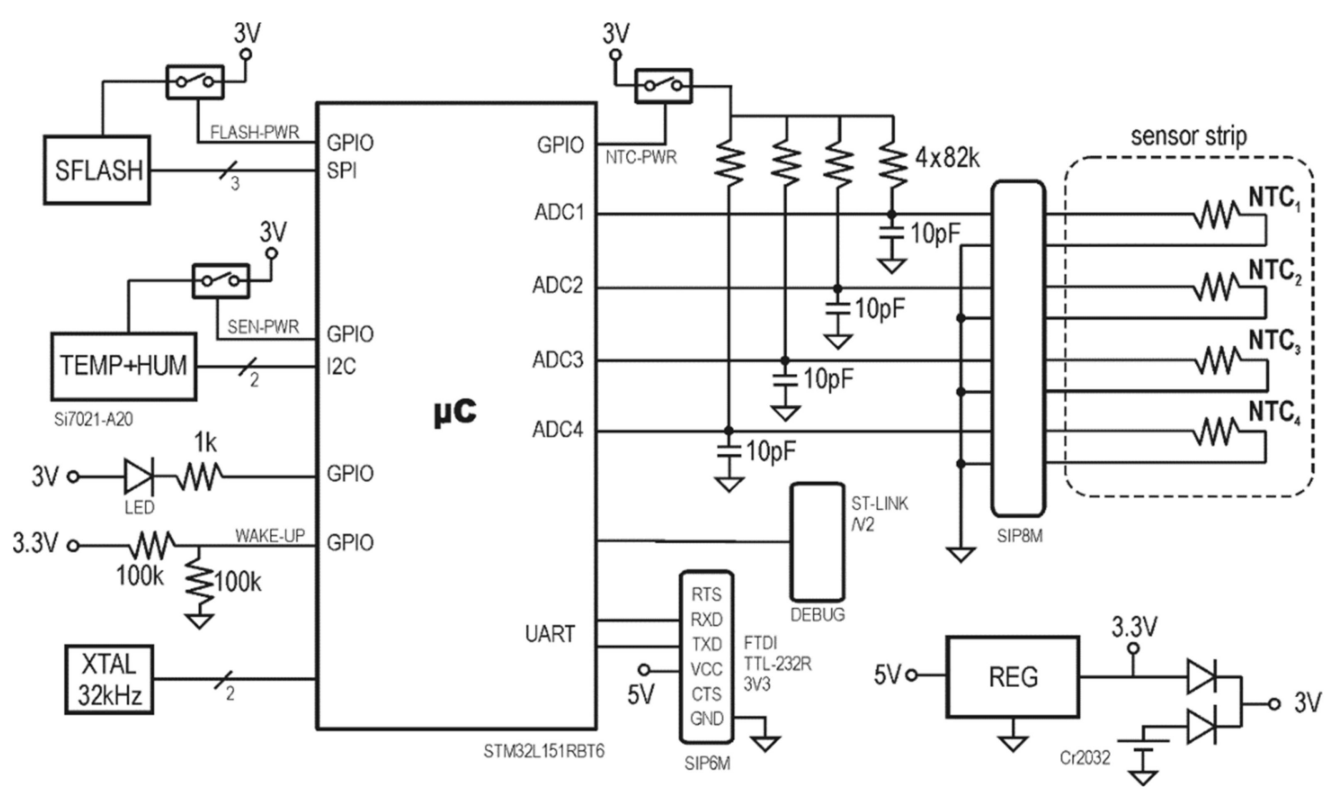

Figure A2. Schematic of the electronic system for temperature measurement. Four analog channels of the microcontroller acquire voltage from the multisensor NTC thermistors. An I2C-communicated (I2C, Inter-Integrated Circuit) sensor (Si7021) sends the external temperature and humidity. A USB interface (through an external FTDI converter) provides communication with PC for data transmission. Autonomous lifetime is ensured by disconnecting devices in sleep mode when battery-powered.

Devices that can consume energy were automatically disconnected during the microcontroller's sleep mode to minimize energy consumption. This extended the useful life of the battery, a CR2032 model with $3.0 \mathrm{~V}$ and a nominal capacity of $210 \mathrm{mAh}$. A low-power LED emitted a brief pulse of light with each reading during stand-alone system operation, allowing operation to be checked. The dump of the data collected in the flash memory 
to the computer was carried out by USB using a wire with an integrated TTL-232R-3V3 converter from FTDI Chip (Future Technology Devices International, Glasgow, UK).

Figure A3 shows the flowchart of the program that managed the acquisition and transmission of data. Once the firmware was loaded into the microcontroller through a single-wire debug (SWD) interface using the programming tool (ST-LINK V2), the system worked autonomously powered by the battery, storing a temperature record per minute (in data-logger mode).

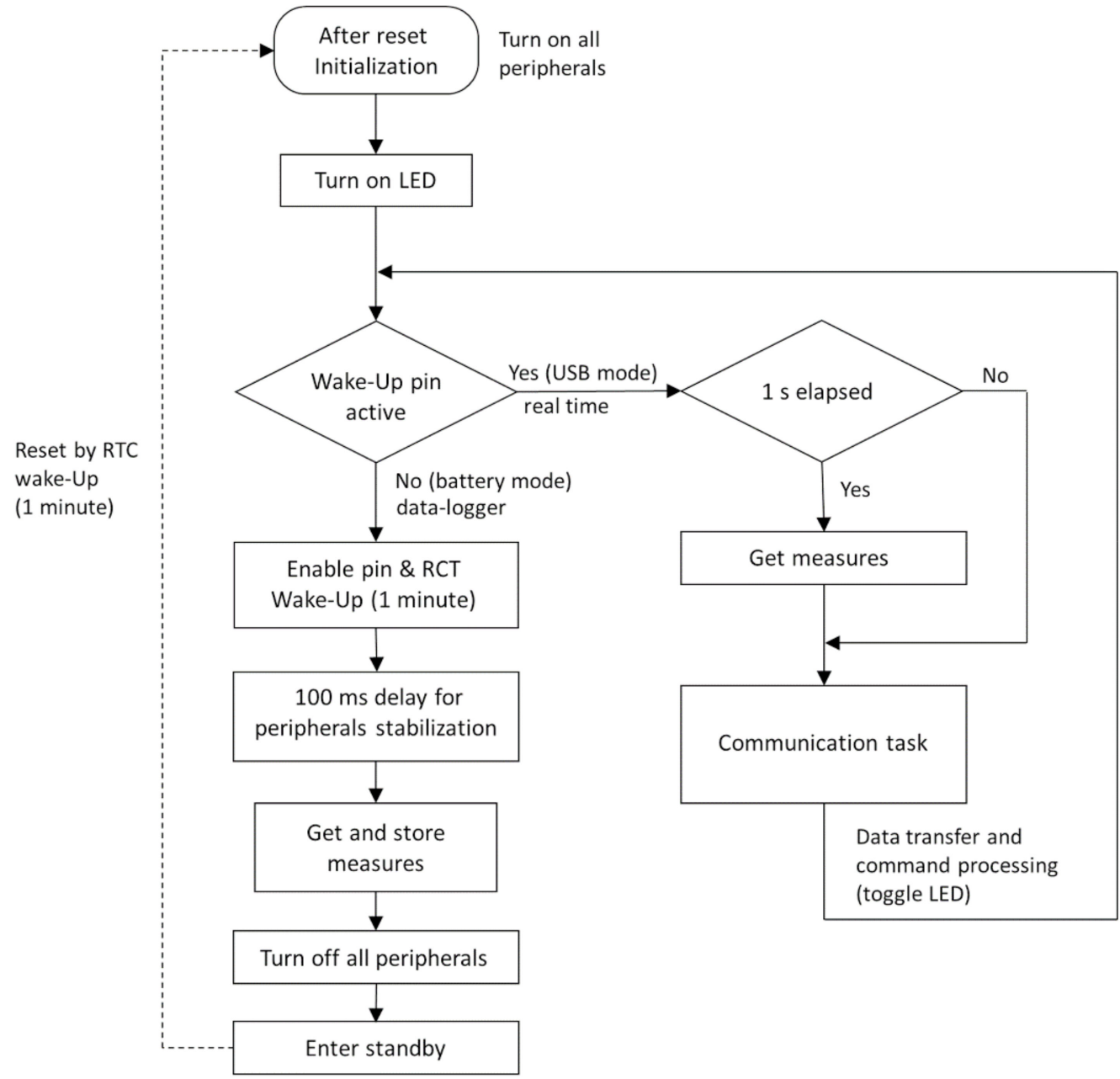

Figure A3. Software flowchart of the electronic system.

When it was connected to the PC through the converter cable, it was powered from the USB. A specific software running on the PC recognized the device and allowed the user to carry out various management operations through a simple user interface (Figure A4) that displayed information about the number of records stored and memory occupancy. Additionally, the system worked as a temperature monitor with a USB connection, offering the readings of the four NTCs plus the external temperature and humidity provided by the integrated sensor. In this case, the samples were updated once a second. The user, from this interface, could update the date, if necessary. The dump of the records stored during stand-alone operation was performed in a CSV file that contained all the relevant information organized in columns with their corresponding headers. In addition to the temperatures, the internal reference voltage value obtained from the power supply was reported. During stand-alone operation, this value was indicative of the state of charge of the battery. 


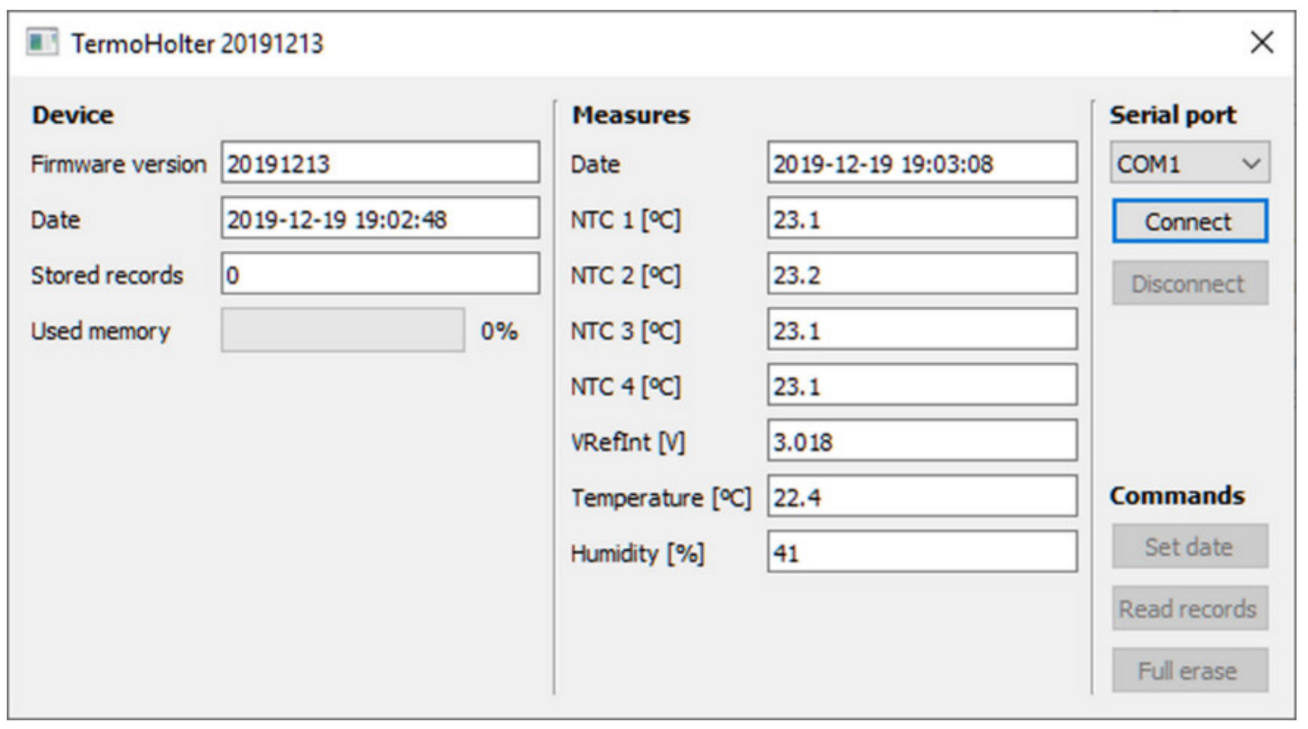

Figure A4. User dialog box with parameter information and configuration.

The device dimensions allowed it to be integrated into the upper part of the wound dressing (Figure A5).
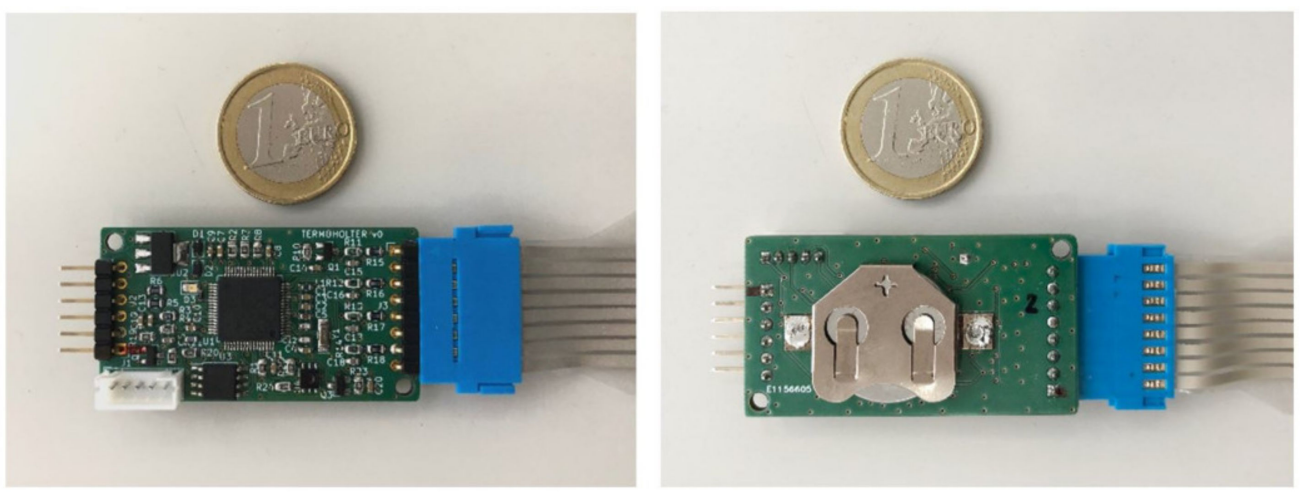

Figure A5. Electronic system (top and bottom views) with the sensor-strip connection.

Appendix A.2. Manufacturing

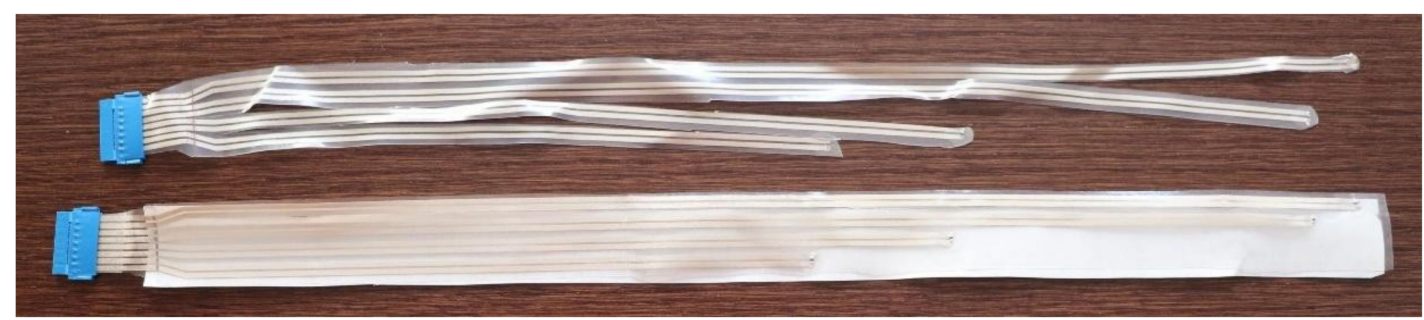

Figure A6. Final prototype. On the bottom, a complete multisensor; and on the top, a multisensor divided by sensors to facilitate its placement.

Appendix A.3. Study of the Polyurethane Films on Fabrics

Figure A7 shows the resistance variation of each pattern of the Inkron IPC-603X screen-printed ink on the DelStar EU50 substrate according to the elongation. The average thickness of the silver layer in the resting state was $4 \mu \mathrm{m}$. 


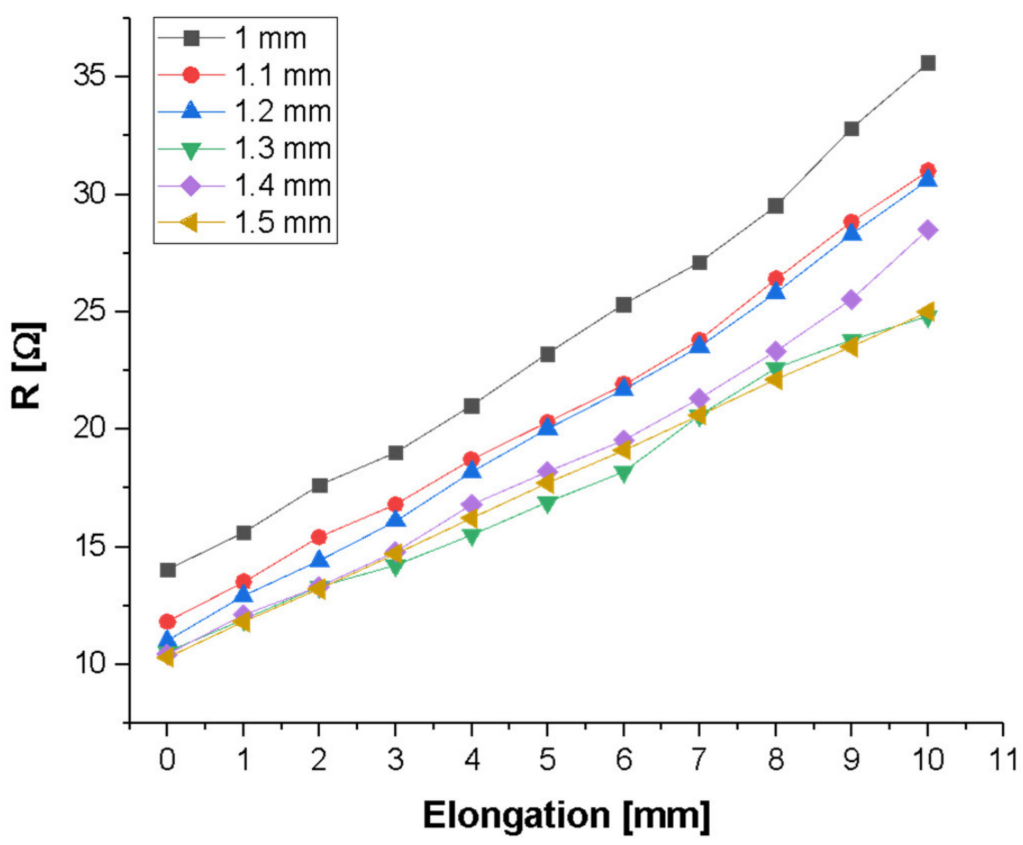

Figure A7. Resistance variation of each pattern of the Inkron IPC-603X screen-printed ink on the DelStar EU50 substrate according to the elongation.

Figure A8 shows the resistance variation of each pattern of the Inkron IPC-603X screenprinted ink on the DelStar EU94DS substrate according to the elongation. The average thickness of the silver layer in the resting state was $1.3 \mu \mathrm{m}$.

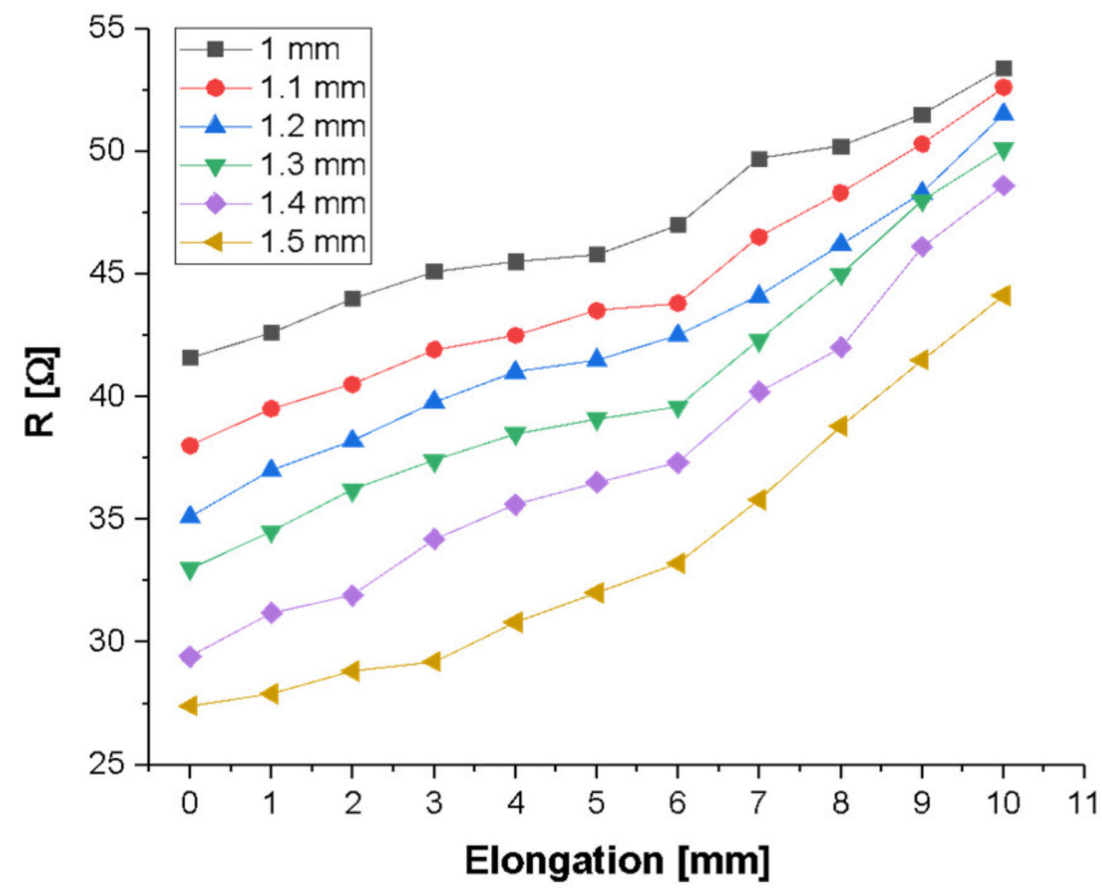

Figure A8. Resistance variation of each pattern of the Inkron IPC-603X screen-printed ink on the DelStar EU94DS substrate according to the elongation.

Figure A9 shows the resistance variation of each pattern of the Inkron IPC-603X screenprinted ink on the Novotex SK81SS+06 substrate according to the elongation. The average thickness of the silver layer in the resting state was $6.1 \mu \mathrm{m}$. Patterns from 1.3 to $1.5 \mathrm{~mm}$ are not shown, as track breaks occurred during the process of elongation between 3 and $4 \mathrm{~mm}$. 


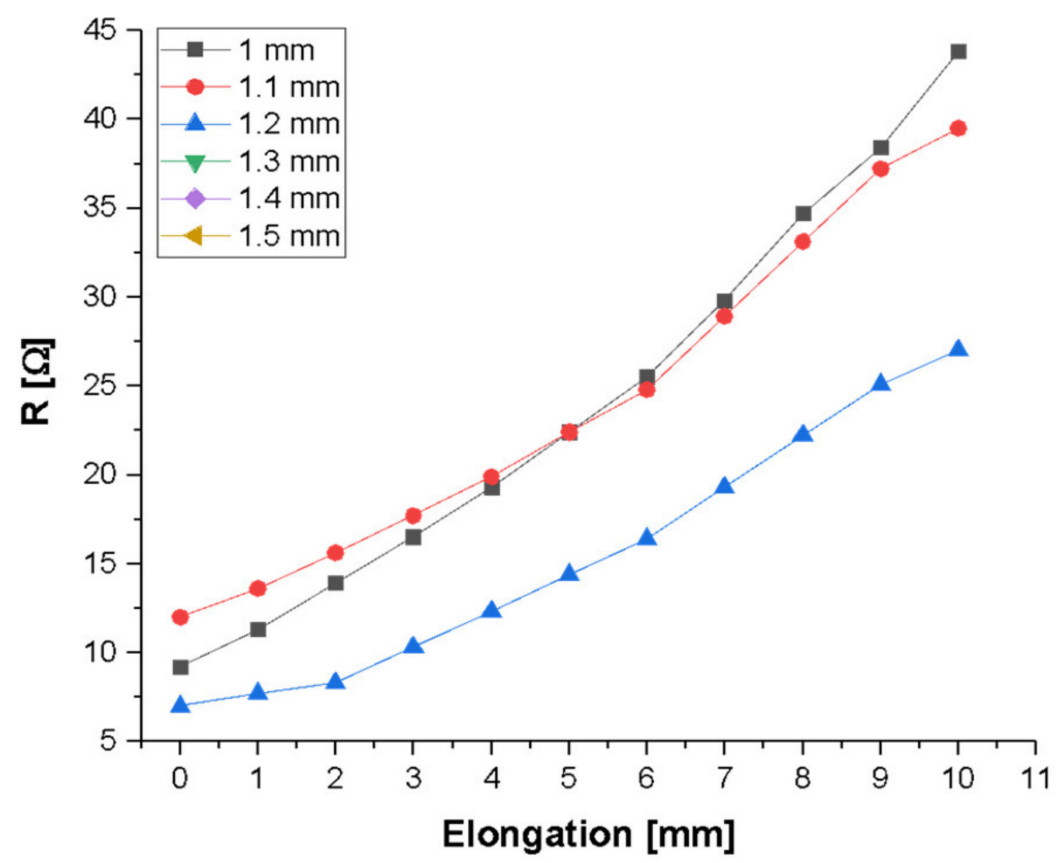

Figure A9. Resistance variation of each pattern of the Inkron IPC-603X screen-printed ink on the Novotex SK81SS + 06 substrate according to the elongation.

Figure A10 shows the resistance variation of each pattern of the DuPont PE873 screenprinted ink on the DelStar EU50 substrate according to the elongation. The average thickness of the silver layer in the resting state was $2.4 \mu \mathrm{m}$.

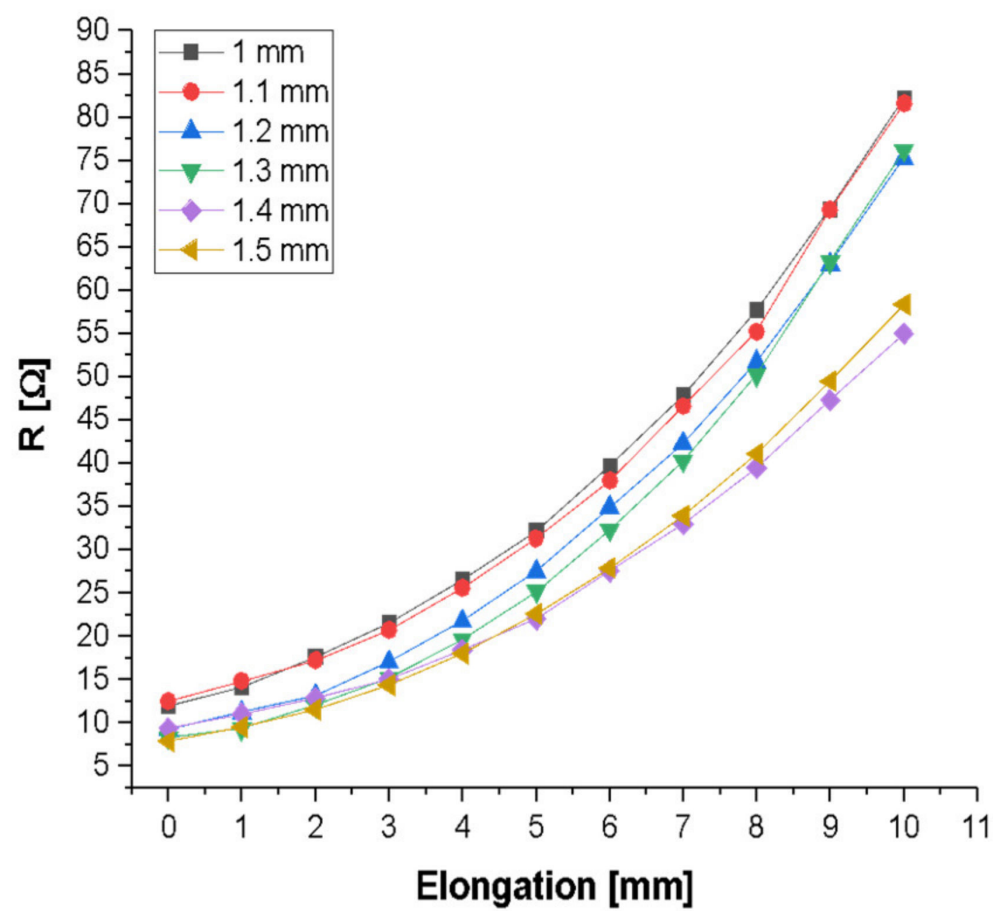

Figure A10. Resistance variation of each pattern of the DuPont PE873 screen-printed ink on the DelStar EU50 substrate according to the elongation.

Figure A11 shows the resistance variation of each pattern of the DuPont PE873 screenprinted ink on the DelStar EU94DS substrate according to the elongation. The average thickness of the silver layer in the resting state was $2.8 \mu \mathrm{m}$. 


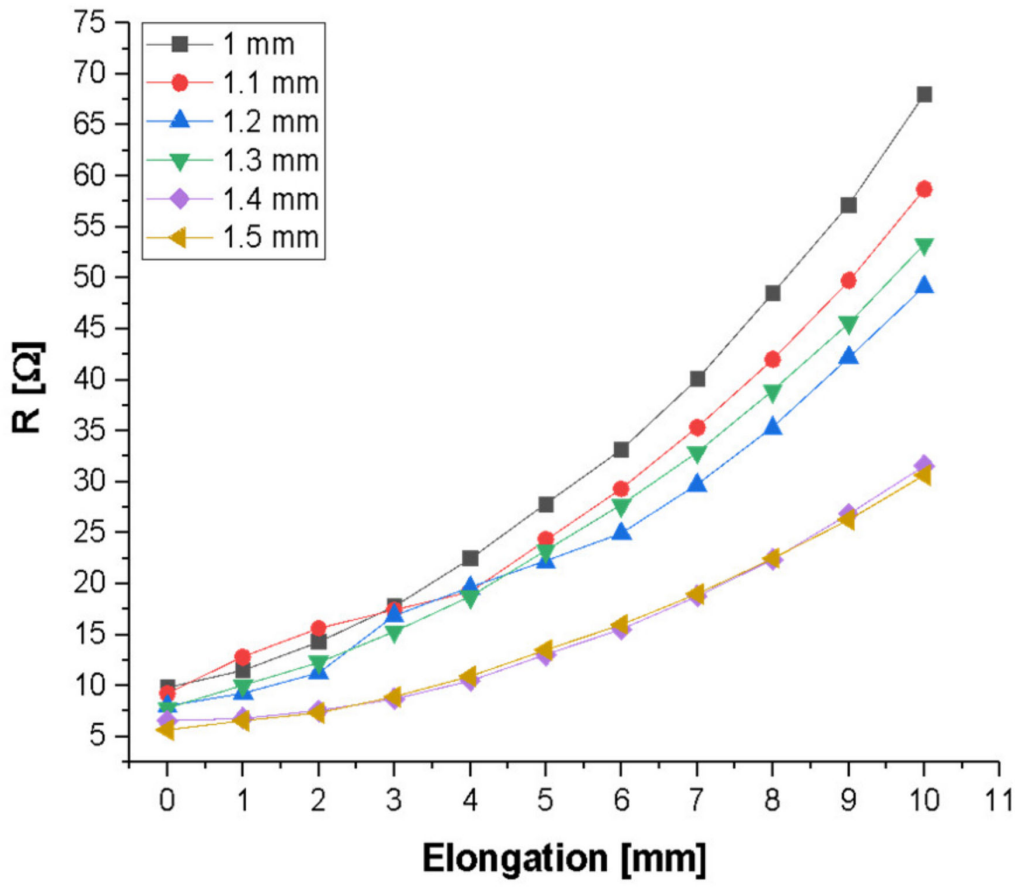

Figure A11. Resistance variation of each pattern of the DuPont PE873 screen-printed ink on the DelStar EU94DS substrate according to the elongation.

Figure A12 shows the resistance variation of each pattern of the DuPont PE873 screenprinted ink on the Novotex SK81SS+06 substrate according to the elongation. The average thickness of the silver layer in the resting state was $4.4 \mu \mathrm{m}$.

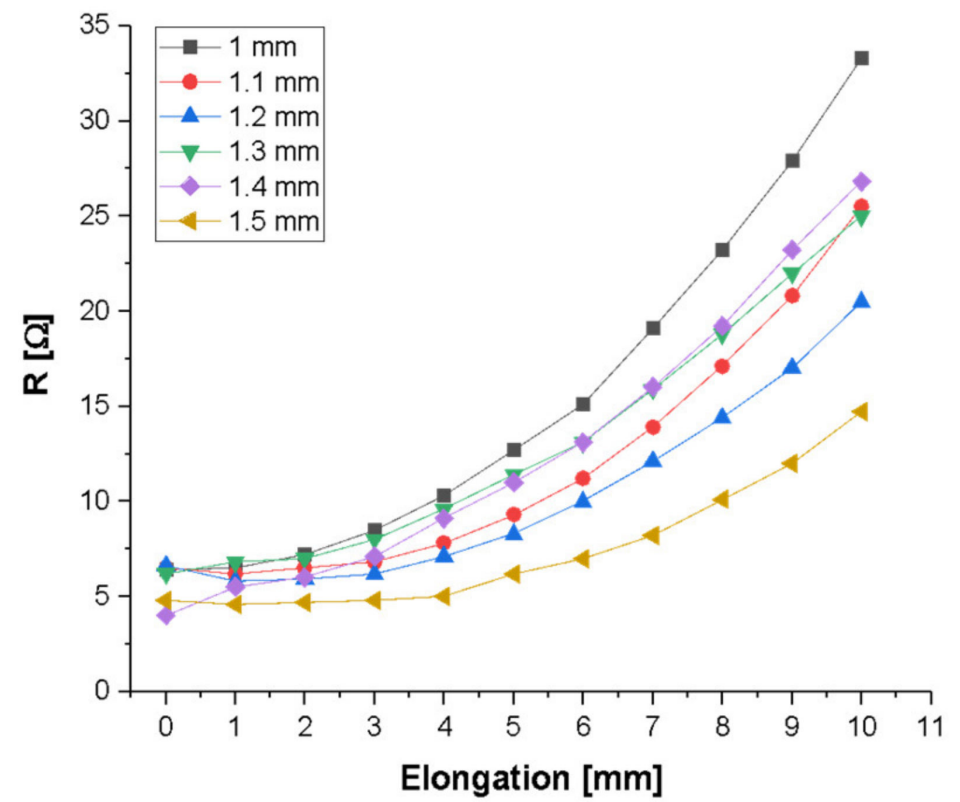

Figure A12. Resistance variation of each pattern of the DuPont PE873 screen-printed ink on the Novotex SK81SS + 06 substrate according to the elongation.

\section{References}

1. Ochoa, M.; Rahimi, R.; Ziaie, B. Flexible Sensors for Chronic Wound Management. IEEE Rev. Biomed. Eng. 2014, 7, 73-86. [CrossRef] [PubMed]

2. Frykberg, R.G.; Banks, J. Challenges in the Treatment of Chronic Wounds. Adv. Wound Care 2015, 4, 560-582. [CrossRef] [PubMed] 
3. Armstrong, D.G.; Lipsky, B.A.; Polis, A.B.; Abramson, M.A. Does Dermal Thermometry Predict Clinical Outcome in Diabetic Foot Infection? Analysis of Data from the SIDESTEP* Trial. Int. Wound J. 2006, 3, 302-307. [CrossRef] [PubMed]

4. Power, G.; Moore, Z.; O'Connor, T. Measurement of PH, Exudate Composition and Temperature in Wound Healing: A Systematic Review. J. Wound Care 2017, 26, 381-397. [CrossRef] [PubMed]

5. Milne, S.D.; Connolly, P. The Influence of Different Dressings on the PH of the Wound Environment. J. Wound Care 2014, $23,53-57$. [CrossRef] [PubMed]

6. Rahimi, R.; Ochoa, M.; Parupudi, T.; Zhao, X.; Yazdi, I.K.; Dokmeci, M.R.; Tamayol, A.; Khademhosseini, A.; Ziaie, B. A Low-Cost Flexible PH Sensor Array for Wound Assessment. Sens. Actuators B Chem. 2016, 229, 609-617. [CrossRef]

7. Milne, S.D.; Connolly, P.; Al Hamad, H.; Seoudi, I. Development of Wearable Sensors for Tailored Patient Wound Care. In Proceedings of the 2014 36th Annual International Conference of the IEEE Engineering in Medicine and Biology Society, EMBC 2014, Chicago, IL, USA, 26-30 August 2014; pp. 618-621. [CrossRef]

8. Suikkola, J.; Björninen, T.; Mosallaei, M.; Kankkunen, T.; Iso-Ketola, P.; Ukkonen, L.; Vanhala, J.; Mäntysalo, M. Screen-Printing Fabrication and Characterization of Stretchable Electronics. Sci. Rep. 2016, 6, 25784. [CrossRef] [PubMed]

9. Matzeu, G.; Losacco, M.; Parducci, E.; Pucci, A.; Dini, V.; Romanelli, M.; Di Francesco, F. Skin Temperature Monitoring by a Wireless Sensor. In Proceedings of the IECON Proceedings (Industrial Electronics Conference), Melbourne, VIC, Australia, 7-10 November 2011; pp. 3533-3535. [CrossRef]

10. Salvo, P.; Calisi, N.; Melai, B.; Cortigiani, B.; Mannini, M.; Caneschi, A.; Lorenzetti, G.; Paoletti, C.; Lomonaco, T.; Paolicchi, A.; et al. Temperature and PH Sensors Based on Graphenic Materials. Biosens. Bioelectron. 2017, 91, 870-877. [CrossRef] [PubMed]

11. Kim, S.J.; Lee, D.S.; Kim, I.G.; Sohn, D.W.; Park, J.Y.; Choi, B.K.; Kim, S.W. Evaluation of the Biocompatibility of a Coating Material for an Implantable Bladder Volume Sensor. Kaohsiung J. Med. Sci. 2012, 28, 123-129. [CrossRef] [PubMed]

12. Rahimi, R.; Brener, U.; Ochoa, M.; Ziaie, B. Flexible and Transparent PH Monitoring System with NFC Communication for Wound Monitoring Applications. In Proceedings of the IEEE International Conference on Micro Electro Mechanical Systems (MEMS), Las Vegas, NV, USA, 22-26 January 2017. [CrossRef]

13. Kassanos, P.; Seichepine, F.; Wales, D.; Yang, G. Towards a Flexible/Stretchable Multiparametric Sensing Device for Surgical and Wearable Applications. In Proceedings of the 2019 IEEE Biomedical Circuits and Systems Conference (BioCAS), Nara, Japan, 17-19 October 2019; pp. 1-4. [CrossRef]

14. Kassanos, P.; Gil-Rosa, B.; Keshavarz, M.; Yang, G. Chapter 2-From Wearables to Implantables—Clinical Drive and Technical Challenges; Sazonov, E., Sensors, W., Eds.; Academic Press: Cambridge, MA, USA, 2021; pp. 29-84.

15. Dini, V.; Salvo, P.; Janowska, A.; Di Francesco, F.; Barbini, A.; Romanelli, M. Correlation between Wound Temperature Obtained with an Infrared Camera and Clinical Wound Bed Score in Venous Leg Ulcers. Wounds 2015, 27, 274-278. [PubMed]

16. McGuiness, W.; Vella, E.; Harrison, D. Influence of Dressing Changes on Wound Temperature. J. Wound Care 2004, 13, 383-385. [CrossRef] [PubMed]

17. Feirheller, M.; Sibbald, R.G. A Clinical Investigation into the Relationship between Increased Periwound Skin Temperature and Local Wound Infection in Patients with Chronic Leg Ulcers. Adv. Skin Wound Care 2010, 23, 369-379. [CrossRef] [PubMed]

18. Mufti, A.; Somayaji, R.; Coutts, P.; Sibbald, R.G. Infrared Skin Thermometry: Validating and Comparing Techniques to Detect Periwound Skin Infection. Adv. Ski. Wound Care 2018, 31, 607-661. [CrossRef] [PubMed]

19. Bach, A.J.E.; Stewart, I.B.; Minett, G.M.; Costello, J.T. Does the Technique Employed for Skin Temperature Assessment Alter Outcomes? Syst. Rev. Physiol. Meas. 2015, 36, R27-R51. [CrossRef] [PubMed]

20. Bach, A.J.E.; Stewart, I.B.; Disher, A.E.; Costello, J.T. A Comparison between Conductive and Infrared Devices for Measuring Mean Skin Temperature at Rest, during Exercise in the Heat, and Recovery. PLoS ONE 2015, 10, e0117907. [CrossRef] [PubMed]

21. Partsch, H.; Mortimer, P. Compression for Leg Wounds. Br. J. Dermatol. 2015, 173, 359-369. [CrossRef] [PubMed] 